\title{
Estimating the scale of profit shifting and tax revenue losses related to foreign direct investment
}

\author{
Petr Janský ${ }^{1} \cdot$ Miroslav Palanský ${ }^{1}$
}

Published online: 10 June 2019

(c) UNU-WIDER 2019

\begin{abstract}
Governments' revenues are lower when multinational enterprises avoid paying corporate income tax by shifting their profits to tax havens. In this paper, we ask which countries' tax revenues are affected most by this tax avoidance and how much. To estimate the scale of profit shifting, we begin by observing that the higher the share of foreign direct investment from tax havens, the lower the reported rate of return on this investment. Similarly to the United Nations Conference on Trade and Development's World Investment Report 2015, we argue that the reported rate of return is lower due to profit shifting. Unlike the report, however, we provide illustrative country-level estimates of profit shifting for as many countries as possible, including low-income ones, which enables us to study the distributional effects of international corporate tax avoidance. We compare estimated corporate tax revenue losses, relative to their GDP and tax revenues, of country groups classified by income per capita and we find that there are almost no statistically significant differences across these groups. Furthermore, we compare our results with four other recent studies that use different methodologies to estimate tax revenue losses due to profit shifting. In the first such comparison made, we find that most studies identify some differences across income groups, but the nature of these differences varies across the studies.
\end{abstract}

Keywords Foreign direct investment $\cdot$ Corporate income tax $\cdot$ Tax avoidance $\cdot$ Base erosion $\cdot$ Profit shifting $\cdot$ Tax havens $\cdot$ Inequality

JEL Classification F21 $\cdot$ F23 $\cdot$ H25

Petr Janský

jansky.peta@gmail.com

1 Faculty of Social Sciences, Institute of Economic Studies, Charles University, Prague,

Czech Republic 


\section{Introduction}

Profit shifting to tax havens by multinational enterprises (MNEs) and the tax avoidance related to this practice represent a crucial issue for the world economy. As we show in this paper's preferred estimates, around $\$ 420$ billion in corporate profits are shifted from the 79 countries in our sample annually, amounting to almost $1 \%$ of these countries' GDP. Using statistics from Tørsløv et al. (2018) for comparison, the shifted profits represent $6 \%$ of all corporate profits and $37 \%$ of MNEs' corporate profits. This estimate implies that at least $\$ 125$ billion is lost in tax revenue, around $10 \%$ of all corporate tax revenue. Our methodology enables us to go beyond these aggregated figures and present estimates of the scale of profit shifting for individual countries.

Tax havens and profit shifting by MNEs have been receiving increasing attention from researchers, policymakers and the media alike, as documented by the recent studies cited in this paper. This is in part because it has become rather easy for MNEs to avoid paying corporate tax, but also, thanks to recent leaks of confidential documents and thorough investigative case studies, it has become relatively easy for the public to learn about it and for researchers to provide evidence of it. Yet, the scale of the tax revenue losses incurred by individual governments remains uncertain due to the inherent difficulties of estimating tax avoidance and due to gaps in the availability of relevant data, some of which are being addressed by recent proposals of the European Union (EU) and Organisation for Economic Co-operation and Development (OECD), and some of which are being overcome by innovative researchers. For example, Bilicka (2019) uses the United Kingdom's confidential corporate tax returns to learn how aggressively foreign MNEs are reducing their corporate tax liability, and Alstadsæter et al. (2019) use audit and leaked data from tax haven institutions to study tax evasion by wealthy individuals. While similar studies do provide rigorous evidence, they are limited in their scope and provide revenue loss estimates for only one or a handful of countries.

In this paper, in contrast, we provide estimates of the scale of profit shifting and the consequent tax implications for as many countries as possible; this requires us to sacrifice rigour to some extent for the sake of improved scope. Specifically, we estimate the scale of profit shifting and tax revenue losses using data on foreign direct investment (FDI). Our two most important data sources are the International Monetary Fund's (IMF) Coordinated Direct Investment Survey (CDIS), which contains bilateral FDI stock data for around 100 countries between 2009 and 2016, and the IMF's Balance of Payments Statistics (BOPS) containing data on FDI income for an even wider set of countries. We begin by observing that a higher share of investment from tax havens (or offshore financial centres-we use both terms interchangeably in this paper) is associated with a lower reported rate of return on inward FDI. We argue, in line with UNCTAD's (2015) World Investment Report, that this pattern is caused by profit shifting and we estimate its scale and the resulting tax revenue losses. Importantly, we present country-level estimates of profit shifting, which enables us to study its impact on the individual countries' government revenues and thus also the distributional impact of profit shifting. Indeed, our main research 
question in this paper is which countries' tax revenues are most affected by international corporate profit shifting.

We estimate the resulting tax revenue losses to understand which countries are losing the most tax revenue relative to their economic size. We compare the results across country groups classified by income per capita and while we do identify some differences in the point estimates, we find that these differences are rarely statistically significant. We further compare our findings with four other studies that have reported country-level tax revenue loss estimates, each of which uses a different methodology: Tørsløv et al. (2018), Cobham and Janský (2018, 2019a) and Clausing (2016). Most of these studies identify some differences across income groups, but the nature of these differences varies across the studies.

This paper's empirical contribution is presented in the following five stages. First, using new and updated data sources, we re-estimate and critically review the work of UNCTAD (2015) in what we call the baseline model. Second, we develop an extended model which improves on the baseline model in a number of aspects. Third, for the first time using this methodological approach, we report country-level estimated tax revenue losses. Fourth, we compare our results with four other recent studies that provide country-level tax revenue loss estimates and this is the first such comparison made. Fifth, we focus on the distributional impact of profit shifting and compare the revenue losses across countries using our estimates as well as those from the other four studies. These five specific stages altogether contribute to the expanding body of literature on profit shifting and tax havens. We make a contribution to the existing research in at least two specific areas. First, we contribute to the ongoing collective attempt to arrive at credible estimates of the scale of profit shifting. Despite the inherent difficulties, discussed for example by Fuest and Riedel (2012), of making such an estimation, a growing number of studies do make estimates of the scale of profit shifting, as our literature review below documents. However, a number of these focus on just one country, such as Gumpert et al. (2016) on Germany or Zucman (2014) on the USA. We develop estimates for a wide range of countries-indeed, for all countries for which we have available data. We see this study as a contribution to international policy debates, since only a limited number of similar estimates are available (and often not for as many countries), and we compare ours to four others that do exist.

Second, we contribute to the study of the heterogeneous impacts of international corporate tax avoidance. So far, most research looks at individual countries or, in the case of an international focus, often concentrates only on the division between developing and developed countries. For example, Fuest et al. (2011) find that the effect of the host country corporate tax rate on the debt ratio of multinational affiliates in developing economies is larger than for affiliates in developed economies. A similar division is used by Johannesen et al. (2017), who link the tax aggressiveness of MNEs with the economic development of their host countries, but they also estimate models that exploit the cross-country variation in economic and institutional development. This more granular approach is needed and similar studies should reflect the country-specific characteristics. In this paper's preferred model, we perform our regression analysis using regional- and income-group fixed effects 
and carry out the rest of the estimation at the country level, at which we also present the results and discuss differences across income groups.

The remainder of this paper is structured as follows. We begin with a brief literature review of related research in Sect. 2 and an overview of the data used and basic descriptive statistics in Sect. 3. We describe our empirical methodology in Sect. 4 and present the results in Sect. 5, in which we also compare our estimates with those reached by other similar papers. Finally, Sect. 6 provides a discussion of the implications of the results and concludes.

\section{Related literature}

In this section, we first discuss the main channels through which MNEs may effectively shift profits out of high-tax jurisdictions. Second, we briefly review recent literature related to the quantification of corporate profit shifting and the resulting tax revenue losses. Third, we sum up the results of a pioneering report by UNCTAD (2015), which developed an FDI-driven approach that we build upon in this paper. Last, before describing our data, we discuss the pros and cons of the data sets most frequently used in similar research and those used in this paper. For the sake of space, we provide only a brief literature review focused on the most relevant research. For more comprehensive reviews of academic literature on profit shifting, we refer to Dharmapala (2014), Clausing (2016) or Dowd et al. (2017).

Three main profit-shifting channels are usually recognised in the literature: debt shifting, the location of intangible assets and strategic transfer pricing. All three are motivated by the MNEs' assumed desire to reduce their global tax liabilities by artificially shifting their profits and assets, and thus tax bases, to countries with lower (effective) tax rates, sometimes referred to as tax havens. First, in the case of the debt shifting channel, MNEs implement unnecessary loans at high interest rates from one MNE affiliate located in a low-tax jurisdiction to another profitable unit located elsewhere (Buettner and Wamser 2013; Desai 2005; Fuest et al. 2011; Huizinga and Laeven 2008). Second, intangible assets and intellectual property, such as brands or research and development, can be stationed artificially at a subsidiary in a tax haven, to which service fees are then paid by other parts of the MNE (Bryan et al. 2017; Dischinger and Riedel 2011; Seabrooke and Wigan 2015; Taylor et al. 2015). As discussed thoroughly by OECD (2017), pricing such intangible assets poses several major challenges, making it intrinsically difficult to disentangle profit-shifting effects from actual prices. The third main channel for profit shifting is to artificially inflate or deflate the prices of goods or services being transferred between the various foreign parts of an MNE in such a way as to minimise the tax burden faced in all the countries put together (Bartelsman and Beetsma 2003; Clausing 2003; Davies et al. 2018; Peralta et al. 2006).

The quantitative evidence of MNEs shifting profits and debt and locating their headquarters or intellectual property in such a way as to avoid tax is substantial. A number of studies have provided evidence of profit shifting, especially on how tax rate differentials affect reported pre-tax profits, and on the strategies MNEs employ to reallocate profits within their groups (Dharmapala and Riedel 2013; Dischinger 
and Riedel 2011; Hines and Rice 1994; Huizinga and Laeven 2008). Although the existing academic and policy studies provide useful guidance on what can be quantified, findings on the implications of tax avoidance for government revenue are rather limited. Among recent exceptions are Clausing (2009), Zucman (2014) and Guvenen et al. (2017), who provide estimates for the USA.

Indeed, for some much-studied countries such as the USA we do not expect the added value of our new estimates to be high; however, for many countries there are no estimates of profit shifting available and that is where we hope to make an important contribution. For developing countries, Johannesen and Pirttilä (2016) provide an overview and Johannesen et al. (2017) offer firm-level empirical results, whereas one of the recent examples of revenue estimates comes from Reynolds and Wier (2016) for South Africa. Furthermore, at least three international organisations have recently developed estimates of the budgetary impact of international corporate tax avoidance for most of the world economy: OECD (2015a), IMF's Crivelli et al. (2016) and UNCTAD (2015). Although these studies make strong assumptions to deal with a lack of any realistic counterfactual data (i.e. what the tax base would be in the absence of profit shifting) and they do not publish country-level results, they do make valuable contributions to the research and have been influential in the policy debate.

We naturally build on a range of existing research in this paper, although we build upon one specific source more than on the others-UNCTAD (2015)'s World Investment Report. In the report, the authors develop an FDI-driven approach (further detailed in Bolwijn et al. 2018a, b) to measure the scale and economic impact of MNEs' tax avoidance schemes. Their investment perspective on tax avoidance puts the spotlight on the role of tax havens as major international investment players. They estimate that some $30 \%$ of cross-border corporate investment stocks are routed through tax havens before they reach their destination as productive assets (Bolwijn et al. 2018b). Their preferred estimate of annual revenue losses for developing countries, the focus of their study, is $\$ 90$ billion; extending that estimate globally results in $\$ 200$ billion, or $8 \%$ of all corporate income tax, lost in government revenue in 2012. In this paper, we review their methodology and, using updated data sources, we extend it to help us better answer our research question. In particular, we present results at the country level and discuss the resulting distributional impacts of profit shifting.

Four other recent papers have presented country-level estimates of revenue losses due to profit shifting for many countries worldwide: Tørsløv et al. (2018), Cobham and Janský (2018), Cobham and Janský (2019a) and Clausing (2016). We compare our findings with the estimates from these four studies in our results section. While they each include an answer to the question of the scale of profit shifting and tax revenue losses for many countries, there are important differences to consider. In particular, each of the four studies uses a distinct methodology (discussed in detail in the papers themselves or in chapter 4 of Cobham and Janský (2019b)), which we now briefly describe.

First, Tørsløv et al. (2018) use national accounts and other data sources, such as balance of payments and foreign affiliate statistics, to estimate the misalignment between the locations of reported profit and real economic activity represented by 
employee compensation. Their methodology is quite straightforward and persuasive, further supported by additional findings on how the profits are shifted. They estimate that around $40 \%$ of MNEs' profits are artificially shifted to tax havens. This is the most recent study and also likely the most reliable source of estimates. In contrast, it is currently not very useful for studying differences across different countries. Although it extends its estimates to the rest of the world, it only covers 37 individual countries, most of them developed, due to the limited availability of national accounts data.

Second, Cobham and Janský (2018) build on the methodology developed by IMF's Crivelli et al. (2016) ${ }^{1}$ and provide a wide coverage of countries, including developing ones. This good country coverage, however, was enabled by their being less demanding with regard to the data, which renders the results less reliable. Specifically, they exploit data on all corporate income revenues, rather than only those paid by MNEs, and do not use any other information on MNEs. The methodology observes the effects of tax havens on other countries' tax bases and assesses the influence of tax havens by turning off these effects, which might include factors other than profit shifting and tax avoidance. These estimates thus capture a broader set of tax avoidance phenomena. As their main results, the authors report long-run estimates which take into account the lagged response of corporate tax base erosion; however, as argued by Tørsløv et al. (2018), this leads to estimates of shifted profits that are often higher than the amount of profits in MNEs. In the comparisons that we make in this paper, we generally consider the short-run, direct estimates as more comparable to the results of other studies, including this one.

Third, Cobham and Janský (2019a) estimate misalignment between the locations of reported profit and real economic activity. They estimate how much additional tax certain countries would collect if MNEs' reported profits were fully aligned with their economic activity, and, inversely, in that hypothetical case how much less tax some other countries-including tax havens-would collect. Together with Tørsløv et al. (2018), Cobham and Janský (2019a) are the only studies that empirically identify tax havens as part of their results. In contrast to the other studies' intended global coverage, Cobham and Janský (2019a) only covers US-headquartered MNEs (US FDI accounts for about a fifth of global FDI) and information on many developing countries are suppressed in their data for confidentiality reasons. Although their estimates are based on FDI data, the identified misalignments are open to other interpretations than profit shifting and they are thus likely to be overestimates.

Fourth, Clausing (2016) derives her revenue effect estimates from the MNEs' profits' sensitivity to lower tax rates. A number of other studies have used a similar methodology for the case of the USA, but no other similar research paper

\footnotetext{
1 The results of IMF's Crivelli et al. (2016) were presented for the first time in their preliminary version in a report by IMF (2014). The report also includes another set of revenue loss estimates due to profit shifting that uses a distinct methodology based on differences in countries' so-called corporate income tax efficiency ratio relative to the average ratio in other countries. Although country-level estimates are presented for this latter methodology, they are perhaps even broader than those of IMF's Crivelli et al. (2016) in what they capture in addition to profit shifting. Because it is not possible to disentangle profit shifting from other factors, which are likely present, we do not include it in our comparisons.
} 
has speculatively extended this methodology to other countries around the world or presented country-level results, as she does.

The data source that many of the recent profit-shifting studies aiming for a wide coverage of countries-including OECD (2015a) and Johannesen et al. (2017) - have used is the Orbis database, the largest commercially available database of company balance sheets. Orbis has the advantage of providing data that enable researchers to produce rigorous estimates about various profit-shifting channels, such as the choice of patent location within MNEs (Karkinsky and Riedel 2012). However, Orbis also has several quite well-known and substantive shortcomings. Most importantly, some countries' companies are more likely to be represented in Orbis than others. As Clausing (2016) has argued, Orbis includes extremely limited information on companies from tax havens and any analysis based on its data thus excludes many observations of incomeshifting behaviour. In fact, Tørsløv et al. (2018) find that only $17 \%$ of global profits of MNEs are observable in Orbis, and Cobham and Loretz (2014) and Kalemli-Ozcan et al. (2015) document that Orbis coverage is severely limited among developing countries in particular. Therefore, as recently acknowledged by Garcia-Bernardo et al. (2017), the Orbis data are tilted against tax havens and developing countries, both of which are crucial for research such as ours. Instead of Orbis, we use country-level FDI statistics that have been employed in various recent studies ranging from Pérez et al. (2012) on illicit financial flows as motives for FDI, to Akkermans (2017) considering the long-term effects of FDI.

The FDI data that we use in this paper are of quality that is sufficient for our purposes. On the one hand, the level of granularity of FDI data remains much lower than that of Orbis and some concerns about data quality are similar to those discussed for Orbis, especially when the data are reported by tax havens. We recognise that there are critical issues related to the data and we discuss at least a couple of them here. First, Haberly and Wójcik (2015) expressed concern about the representativity of FDI data. Second, FDI data are based on the immediate investor approach and do not enable us to distinguish whether an investor country is only a conduit or represents the real origin of the investment. Damgaard and Elkjaer (2017) empirically highlight the difference between using immediate counterparts and ultimate investing countries. Third, FDI data include information on the activity of the so-called special-purpose entities; we discuss this in the methodology section below. On the other hand, the extensive coverage of countries, and developing countries in particular, makes the FDI data superior to Orbis for our purposes. To the best of our knowledge, these are the most reliable data currently available, and we thus use them despite their limitations. We believe that both the Orbis and FDI data sets should be used for research into profit shifting and that their results can complement each other. Given the better country coverage of the FDI data, our empirical approach is apt for estimating the global distribution of profit shifting and the scale of the resulting tax revenue losses. 


\section{Data}

Our approach uses the leading data sources with country-level information on FDI. We use bilateral data on FDI stocks from the IMF's Coordinated Direct Investment Survey (CDIS), which contains data for up to 112 countries between 2009 and 2016 (IMF 2018). For stocks of direct inward investment, we use the variable 'Inward Direct Investment Positions, US Dollars (IIW_BP6_USD)'. Bilateral data are needed to calculate the share of FDI from tax havens, which is our main explanatory variable in the core regressions. In addition, to identify FDI attributable to specialpurpose entities (SPEs) in the countries that allow these entities to exist, we use the OECD's Foreign Direct Investment Statistics, which is the only source of FDI data that distinguishes between investment by SPEs and other firms, albeit for OECD countries only. ${ }^{2}$

The volume of the total global stock of international direct investment rose substantially over the observed time period, as shown for countries classified into income groups and regions in Figs. 6 and 7 in Appendix. While in 2009 the total global FDI stock amounted to \$18.7 trillion, in 2016 it was \$27.7 trillion-a 48\% increase. All groups increased their FDI stock except one-the Middle East and North Africa lost $69 \%$ of its FDI stock, likely due to the combined effect of declining oil prices, the Arab spring and military conflicts in the region. The significant increase (by 1.382\%) in South Asia's FDI stock between 2009 and 2015 is caused by the lack of data for India in 2009-if we use India's 2010 value to compute the difference over the observed time period, we arrive at a modest $43 \%$ increase. We observe that the increase in total FDI stock was caused by investment from both tax havens (whose classification we explain in the following section) and other countries.

We also need information on FDI income, which we source from the IMF's Balance of Payments Statistics (IMF, 2013). Specifically, we use three variables from this source: (1) the overall FDI income (the variable 'Current Account, Primary Income, Investment Income, Direct Investment, Debit, USD (BMIPID_BP6_ USD)'); (2) the equity component of FDI income (the variable 'Current Account, Primary Income, Investment Income, Direct Investment, Income on Equity and Investment Fund Shares, Debit, US Dollars (BMIPIDE_BP6_USD)'; and (3) the debt component of FDI income (the variable 'Current Account, Primary Income, Investment Income, Direct Investment, Interest, Debit, US Dollars (BMIPIDI_ BP6_USD)'). We then compute the three corresponding rates of return on FDI (overall, equity component, and debt component) as the ratio of the corresponding FDI income to the total FDI stock in each country. While we believe that this is the best approach, it comes with three limitations. First, while investment from different countries may yield different returns across countries, the FDI income data are only available at country level (and not at a bilateral level), which hides some of the

\footnotetext{
${ }^{2}$ Only two countries that do not report this data in the OECD FDI Statistics and are known to allow SPEs are Luxembourg and Austria, for which we use the estimates of SPE shares provided by UNCTAD (2015) based on data from these countries' central banks.
} 
information that could potentially be used to obtain better estimates of the size of corporate profit shifting (for example by distinguishing between FDI income from tax havens and from other countries; such data are available for OECD countries, but not for the majority of other countries, including developing ones). Second, although both sources (for FDI income and FDI stocks) that are combined into a single number (the rate of return on FDI) come from the IMF, they may use slightly inconsistent methodologies to identify what is classified as FDI. Third, while we use not only the overall FDI income, but also its equity component and its debt component, we divide all these three measures of FDI income by the same overall FDI stock, rather than the equity component and the debt component of the FDI stock. Despite these data limitations, we believe that these sources provide us with as good information as there is on the true rate of return on FDI.

In addition to data on FDI, our methodological approach requires data sources that are auxiliary to the main analysis, including data on corporate tax rates from KPMG (2018) and the World Bank (2016), lists of tax havens from various sources, and data on GDP from the World Bank, complemented, where missing, by data from the United Nations (2018) and the CIA (2018). To present the estimates in relative terms to tax revenues, we use data from the ICTD/UNU-WIDER's (2018) Government Revenue Dataset. We present summary statistics of the variables used in the analysis in Table 3 in Appendix.

\section{Methodology}

In this section, we describe the empirical strategy that we use to estimate the scale of profit shifting. Since profit shifting is inherently difficult to observe directly, the existing methodological approaches aim to indirectly shed more light on certain aspects of profit shifting. In this paper, we build on one such approach developed by UNCTAD (2015) and detailed by Bolwijn et al. (2018a), which we extend further to provide the answer to our main research question: which countries' corporate tax revenues are most affected by profit shifting? We begin by describing how we empirically test whether higher shares of FDI from tax havens are associated with lower reported rates of return on inward FDI. We then outline how we use these models to derive estimates of the scale of profit shifting and the resulting tax revenue losses. The final part of this section explains in detail how we define the share of FDI from tax havens in total inward FDI in each country, which we use as an input in the first part.

We begin by explaining the logic of the hypothesis that countries with a higher share of foreign direct investment originating from tax havens tend to have lower rates of returns on FDI. The proposition central to our analysis is that a higher share of FDI from tax havens is associated with a higher tendency to shift profits to these tax havens, resulting in an artificially deflated reported rate of return on FDI. This proposition is in line with all three main channels of profit shifting recognised in the literature (i.e. debt shifting, trade mispricing, and location of intangibles). First, debt shifting to tax havens through inflated interest rate payments should lower the rates of return reported in countries that receive a lot of investment from tax havens. 
While there is some evidence that the debt shifting channel is not very important (Heckemeyer and Overesch 2017), no detailed quantification of the various channels seems yet to have been published. Second, when intangible assets are located in tax havens so that other countries need to pay for their use, this also lowers their reported rate of return. Third, if an MNE unit based in a tax haven artificially inflates exports to MNE units located in other countries, then this trade mispricing is consistent with lowering the rate of return in these other countries as well. Therefore, we conclude that all these main channels of profit shifting should be reflected in the observed relationship between the rate of return on FDI and the share of FDI from tax havens. We acknowledge that there are some profit shifting schemes that would not show up in the FDI data (for example, a natural person that unofficially controls two separate entities that operate in two different countries may artificially shift profits across border through fictitious invoicing between these officially unrelated parties with no trace in the FDI data) or are otherwise not captured by our approach (such as the case, discussed below, when parent companies in non-havens shift profits to subsidiaries in tax havens). Overall, while some tax avoidance schemes remain beyond the reach of our empirical strategy, we argue that it is able to capture the three main channels.

We empirically estimate the relationship between the rate of return on FDI and the share of FDI from tax havens using two models. For both models, we follow UNCTAD (2015) and we drop 9 outliers displaying extreme values of rate of return or the share of investment from tax havens. The first model is a baseline one that follows the UNCTAD (2015) methodology as closely as possible but uses updated data; the second is an extended model which, in addition to the year fixed effects and region-group fixed effects included in the baseline model, also includes incomegroup fixed effects and interaction terms with both regional- and income-group effects. More formally, in our baseline model, the regression to be estimated using ordinary least squares (OLS) with regional and time fixed effects is:

$$
\text { FDI_ROR }{ }_{i t}=\beta * \text { share_havens }_{i t}+\sum_{s=2009}^{2016} \delta_{s} z_{s, i}+\sum_{k=1}^{7} \phi_{k} d_{k, i}+\varepsilon_{i t},
$$

where FDI_ROR ${ }_{i t}$ is the rate of return on FDI in country $i$ in year $t$, share_havens ${ }_{i t}$ is the share of FDI from tax havens in country $i$ in year $t, z_{s, i}$ are year fixed effects, and $d_{k, i}$ are regional fixed effects based on the World Bank's classifications. The rationale behind using regional fixed effects is that some regions share common characteristics that have significant effects on both the explanatory and dependent variables. We focus on two definitions of the rate of return - the overall rate of return and its equity component - and for both of these we hypothesise a negative relationship. In contrast, we expect a positive parameter estimate for the debt component since it is composed primarily of interest paid by the foreign affiliates to the parent, which is, in fact, a cost for the affiliates that is not subject to corporate income taxation.

In the second part of our empirical analysis, we propose an extended model: 


$$
\begin{array}{rl}
\text { FDI_ROR }_{i t}= & \alpha * \text { share_havens }_{i t}+\sum_{m=1}^{5} \beta_{m} * \text { share_havens }_{i t} * \text { inc }_{m, i} \\
& +\sum_{k=1}^{7} \gamma_{k} * \text { share_havens } \\
i t & * d_{k, i}+\sum_{m=1}^{5} \delta_{m} i n c_{m, i}+\sum_{k=1}^{7} \phi_{k} d_{k, i}+\sum_{s=2009}^{2016} \theta_{s} z_{s, i}+\varepsilon_{i t},
\end{array}
$$

where inc $_{m, i}$ are dummy variables for income groups (as per the classification by the World Bank), with the remaining notation the same as in the baseline model.

Our extended model makes two main innovations over the baseline model. First, we use a more granular definition for developing countries, which is based on the World Bank's classification of countries by income per capita. Specifically, we add controls for income groups in our model, using dummy variables in the full-sample regression, rather than splitting the sample for developing and developed countries and performing the regressions separately, allowing for improved explanatory power. Including income-group fixed effects is also a step towards a model with country fixed effects, which would likely be a first-best model, but the data do not enable it because of the short period for which they are available and the low levels of variation in inward FDI stock and rate of return on FDI. While it would be desirable to account for countries' fixed effects in the estimation, the host country-fixed effects estimation results are not robust and mostly not statistically significant. Nevertheless, some specifications provide additional empirical support for our extended model (for example, a subsample of 69 countries for which all 7 yearly observations are available suggests a statistically significant negative estimate of the coefficient of a similar magnitude as reached by the estimates of our extended model). Given that the fixed effects model is not robust, we consider our extended model to be the best option for an estimation of the scale of profit shifting.

The second main innovation is that the extended model allows for effects that are heterogeneous across regions and income groups to influence the relationship between the share of FDI from tax havens and the rate of return on FDI. This addition is enabled by interaction terms for income and regional groups with the share of FDI from tax havens. The regional and income-group effects are thus implicitly divided into those that affect the examined relationship and those that do not. The rationale behind this process is that the countries within these groups share some common characteristics that have a specific effect on the behaviour of the MNEs that route their investment through tax havens. Our approach allows us to capture these common effects. We also carry out a series of robustness tests to check the sensitivity of our results to the separate inclusion of regional- and income-group interaction terms.

While these two main innovations improve on the baseline model, there is an important assumption that we need to make for both the baseline and extended models. Namely, we argue that the negative relationship between the share of FDI from tax havens and the rate of return on FDI is due to profit shifting. There are at least two reasons to support this argument. First, as argued above, the observed negative relationship between the share of FDI from tax havens and the reported rates of return on FDI is consistent with all three main channels of profit shifting. Second, 
a wide body of literature has shown that profit shifting to tax havens leads to lower reported rates of return. For example, there is such evidence for developing countries (Fuest and Riedel 2012) as well as more recently for the USA (Wright and Zucman 2018). On the basis of these reasons, we argue that the reported rate of return is lower due to profit shifting. While we believe that our argument reflects the reality, we also recognise several factors that might lead to underestimation or overestimation, on balance most likely an underestimation, of the true size of the relationship.

First and foremost, we underestimate the scale of profit shifting by not capturing all tax avoidance schemes. The approach in this paper focuses on FDI from tax havens in other countries and it thus only captures profit shifting from subsidiaries located in non-havens to parent firms located in tax havens. Our estimates do not capture any profit shifting from parent companies in non-havens to subsidiaries in tax havens (e.g. the case of Apple Inc., headquartered in the USA with a subsidiary in Ireland). As a result, our estimates are likely underestimates of the true scale of overall profit shifting. Second, the rate of return in a hypothetical case of no profit shifting might be higher than what we assume it to be, which would lead to a downward bias. Every country has some FDI from tax havens, but our regression approach considers those with little FDI from tax havens as the implicit profitability benchmark for those with more FDI from tax havens. In reality, a benchmark closer to the true value might be the profitability of otherwise comparable local companies (i.e. those with no profit shifting at all). If this is the case, and Tørsløv et al. (2018) provide some related empirical support for this view, we might be underestimating the scale of profit shifting. Third, our estimated relationship might suffer from attenuation bias towards zero, also because our preferred specification is quite restrictive of the data. Any incomplete tax haven investment data coverage, as discussed above, might underestimate the share of FDI from tax havens and thus contribute to underestimation of the scale of profit shifting. Fourth, since data on FDI income is not available on a bilateral level, we instead use the FDI income information at the country level, averaging out the values - rather than having it (likely) lower for tax havens and higher for other countries - and this might lead to an underestimation of the relationship. Overall, in particular because of the first of these reasons, we believe that our results are lower-bound estimates.

On the other hand, we acknowledge that the reported rate of return might be lower due to reasons unrelated to profit shifting, potentially leading to an upward bias. There may be other reasons why FDI from tax havens yields lower rates of return than other FDI, for example, its different sector-, risk- or expected yieldcomposition. To the extent that this is the case, we might overestimate the scale of profit shifting. ${ }^{3}$ Conversely, we also recognise that the reported rate of return might

\footnotetext{
${ }^{3}$ In case our empirical approach led to an overestimation of the scale of profit shifting, the extent of the overestimation would be proportional. For example, if profit shifting was responsible for only three quarters of the lower rate of return, then the scale of profit shifting would be lower by one quarter than that estimated in this paper. In the results sections we do not provide results with adjustments for this because we do not have any information in our data or the existing literature to derive these numbers using specific estimates and also because the adjustment for the potential overestimation is proportional and thus empirically straightforward on the basis of our results.
} 
be higher due to reasons unrelated to profit shifting and, in that reverse case, similar logic would imply that we might be underestimating profit shifting. This is an empirical question, but unfortunately the FDI data are only available at country-, rather than industry- and other disaggregated level, which prevents further improvement in the precision of the estimation in this respect. Overall, there does not seem to be a credible way to establish empirically the extent to which the negative relationship is or is not driven by profit shifting. We argue that our assumption on balance likely reflects the reality; nevertheless, this implies that we should be careful when interpreting and using these illustrative estimates of profit shifting.

Once we obtain the estimate of the relationship between the share of FDI from tax havens and the rate of return on FDI, we can estimate how much profit is shifted and what the associated tax revenue losses are for the affected countries. Specifically, we multiply the responsiveness of the reported rate of return to the share of FDI from tax havens - a parameter estimated by the regression above-by the actual value of FDI from tax havens. Then, to arrive at an estimate of the associated tax loss, we transform the estimates of shifted profits to pre-tax values, an adjustment which is necessary because the original FDI data are after-tax. Finally, we multiply these estimates of pre-tax shifted profits by the relevant statutory tax rate (which implies that all the shifted profits would, had they not been shifted, have been liable to corporate income taxation). For the global baseline model, we do so in the same straightforward way as UNCTAD (2015), using total global values for FDI stock and average values for the share of FDI from offshore financial centres and the corporate tax rates. ${ }^{4}$ In contrast, for the extended model, we use country-specific values for these variables whenever available. So, for example, we calculate the country-level estimates using specific corporate tax rates for each country rather than one estimate for all countries. This, together with the region- and income-group fixed effects, makes the extended model more reliable than the basic model at the country level.

We now return to explaining how we define the share of FDI from tax havens that each country receives. In principle, it would be desirable to use relevant observable characteristics of tax havens and other investor countries, which could help us determine which individual tax havens are responsible for the tax revenue losses incurred by other countries. The inclusion of origin-country time-varying controls in the regression could enable us to control for characteristics of origin countries that might systematically vary between tax havens and other investor countries. In reality, however, there are hardly any data available other than FDI, GDP and some other basic economic variables for some of the tax havens in our analysis, and therefore it is not possible to control for any observable origin-country effects, either fixed or time-varying. Instead, we mostly rely on tax haven classifications and the available FDI-related data.

\footnotetext{
4 UNCTAD's (2015) approach can be summed up as follows (with their headline numbers for 2012 for developing countries in parentheses): corporate income tax revenues lost due to profit shifting for developing countries $=$ average tax haven exposure of total inward FDI stock $(46 \%) \times$ reported FDI stock ( $\$ 5000$ billion) $\times$ responsiveness of reported rate of return on tax haven investment $(15.8 \%) \times$ transforming the after-tax values to pre-tax values $(1.25) \times$ weighted average effective tax rate $(20 \%)=\$ 91$ billion.
} 
In particular, we identify tax havens, or offshore financial centres, in three categories, mostly following UNCTAD (2015). First, we use a list of 38 tax havens compiled by UNCTAD (2015) based on OECD's (2000) initial list of 41 jurisdictions. ${ }^{5}$ The whole stock of FDI originating from these jurisdictions is considered offshore investment. ${ }^{6}$ The second is a group of so-called self-declared special-purpose entity (SPE) countries. An SPE is an institutional unit set up to provide financial services to MNEs that allow it to transfer funds through a jurisdiction. These entities are sometimes called pass-through units or shell companies because the financial flows administered by these entities do not correspond to their actual economic activities in the SPEs' country of incorporation (OECD, 2015b). Primarily, we use data published by the OECD to determine the average share of SPE-related FDI stock in the overall outward FDI of the 12 countries that report this data. ${ }^{7}$ Following UNCTAD (2015), for two other countries, we use data available from their corresponding central banks (Austria, 36\%, and Luxembourg, 96\%).

The final, third group of tax havens are 'other SPE countries', which do not declare themselves to be SPE-enabling countries, but seem to behave as such. We identify other SPE countries in the same way as UNCTAD (2015), proceeding in two steps. In the first step, we identify countries that have been successful in becoming important offshore financial centres. We classify a country as an 'other SPE country' if, as of 2016 data, it: (1) ranks in the first quartile in terms of inward FDI stock; and (2) it has a ratio of inward FDI stock to GDP of more than 1. For 2016 data, we identify 26 countries complying with the first criterion and 20 with the second, with nine countries at the intersection of these two groups (complying with both criteria). Excluding tax havens and self-reported SPE countries (which were already handled in the first two groups) results in four countries being classified into the final 'other SPE countries' group. In the second step, we consider these four countries and calculate the level of investment implied by the size of their economy (based on a simple OLS cross-country regression of reported inward FDI on GDP in 2016). The difference between the actual FDI stock and the predicted FDI stock is

\footnotetext{
5 Our list of 38 tax havens is the following: Anguilla, Antigua and Barbuda, Aruba, Bahamas, Bahrain, Belize, Bermuda, British Virgin Islands, Cayman Islands, Cook Islands, Cyprus, Dominica, Gibraltar, Grenada, Guernsey, Isle of Man, Jersey, Liberia, Liechtenstein, Malta, Marshall Islands, Mauritius, Monaco, Montserrat, Nauru, Netherlands Antilles, Niue, Panama, Saint Kitts and Nevis, Saint Lucia, Saint Vincent and the Grenadines, Samoa, San Marino, Seychelles, Turks and Caicos Islands, US Virgin Islands, Vanuatu.

6 We acknowledge that this method partly relies on somewhat arbitrary decisions about the criteria for the dichotomous selection of tax havens, which have been criticised for example by Cobham et al. (2015). Indeed, we would prefer to use a continuous measure that does not rely on binary criteria. The way we identify tax havens in three groups at least combines binary with continuous measures but, to our knowledge, there is currently no such single continuous measure for offshore investments. In addition, we carry out robustness checks using other lists of tax havens and reach similar results.

7 These countries and their corresponding average shares of SPE-related outward FDI in 2016 are: Belgium (3.5\%), Denmark (13.7\%), Estonia (4.1\%), Hungary (83.9\%), Iceland (38.4\%), Netherlands $(65.2 \%)$, Norway $(0.3 \%)$, Poland (1.2\%), Portugal (13.6\%), South Korea $(0.001 \%)$, Spain (4.7\%) and UK $(10.5 \%)$. In addition, two countries are known to allow SPEs and do not report this data in the OECD FDI Statistics, and we thus use estimates by UNCTAD (2015) based on data from these countries' central banks-Luxembourg (95\%) and Austria (36\%).
} 
then accounted towards the share of FDI from tax havens (Hong Kong, 89.9\%, Ireland, $80.3 \%$, Singapore, $85.7 \%$, and Switzerland, $74.5 \%$ ). Combined, the three categories contribute to how much each country receives in inward FDI from tax havens relative to its total inward FDI. This figure feeds into the regression at the beginning as an explanatory variable and we also begin the discussion of our results with it.

\section{Results}

We present our empirical results in this section. First, we present estimates of the baseline model using updated data sources. Second, we estimate the newly developed extended model and present its estimates of profit shifting and the resulting tax revenue losses. Third, we compare our results with four other similar studies and highlight their relevance for the cross-country distributional impact of international corporate profit shifting.

We begin with the results of the estimation of the baseline model. For both the rate of return and its equity component, we find a statistically significant negative relationship between the share of inward FDI originating from tax havens and the rate of return on FDI. We report the detailed results in Table 4 in Appendix. ${ }^{8}$ Compared to the estimations carried out by UNCTAD (2015), we use data for all countries for which it is available in the period 2009-2016, increasing the sample from 265 to 614 observations. Following UNCTAD (2015) to ensure comparability, we then divide the sample into two groups-developing and developed countries - and estimate the model for three alternatives of the dependent variable: the overall rate of return on FDI and its equity and debt components. Our results suggest slightly smaller coefficients in absolute value, except for the model that only includes developed countries, where we find a slightly higher effect, statistically significant at the $1 \%$ level. Furthermore, we obtain statistically insignificant positive coefficients for the model that uses the debt component of the FDI rate of return as the dependent variable. This positive coefficient is in line with the notion that the debt component is composed primarily of interest paid by foreign affiliates to the parent, which is, in fact, a cost for the affiliates and thus an element that actually erodes the taxable base. In the remaining part of our analysis, including the extended model, we focus only on models that use the equity component of the rate of return or the overall rate of return itself, while preferring the equity component models due to their higher relevance for profit shifting by MNEs.

We use the baseline model's results to derive an estimate of the scale of profit shifting, both worldwide and for individual countries. Table 5 in Appendix summarises the results for 2016. We use information on the total global exposure to tax haven investment $39.5 \%$ for all, $49 \%$ for developing and 35\% for developed

\footnotetext{
${ }^{8}$ As an example, let us consider the parameter estimate of -.0713 for the independent variable, the share of FDI from tax havens, in the specification whose dependent variable is the equity component of FDI rate of return. This estimate implies that every one percentage point increase in the share of FDI from tax havens is associated with a lower rate of return by 0.0713 percentage point.
} 
countries) and the total reported FDI stock (\$16.68 trillion for all, $\$ 10.51$ trillion for developed and $\$ 6.18$ trillion for developing countries). One option to derive an estimate of profit shifting is to use the regression estimates for all countries from Table 4. By doing so, using our preferred model with the equity component of the rate of return as a dependent variable, we arrive at a global estimate of $\$ 665$ billion in shifted profits, and a corresponding \$194 billion lost in tax revenues in 2016. Even in relative terms, these are large numbers-according to these estimates, around $0.9 \%$ of the world's GDP or $5.8 \%$ of all corporate profit is shifted to tax havens. Tørsløv et al. (2018) report that the profits of foreign corporations in 2015 amounted to around $\$ 1.7$ trillion and that close to $40 \%$ of these reported profits were shifted, and our estimates from the global baseline model reach similar numbers. Regarding tax revenue, the estimate of $\$ 194$ billion in global corporate tax revenue foregone due to profit shifting means that $9.8 \%$ of the total corporate tax currently collected is avoided by MNEs.

While the obvious advantage of using this baseline model is that we obtain estimates of profit shifting and tax losses for all countries (except, naturally, for tax havens and SPE countries), one drawback is that it averages out significant heterogeneity across countries. Therefore, we consider more granular options, starting with one that divides the sample into two groups-developing and developed countries. Our results for 2016, presented in detail in Table 5 in Appendix, show similar results to those reached by UNCTAD (2015) for 2012. While our estimated coefficient from the regression is slightly lower, the total FDI stock in developing countries increased from $\$ 5$ trillion in 2012 to $\$ 6.18$ in 2016, leading to estimates of similar magnitude $-\$ 83$ and $\$ 95$ billion lost in tax revenue in developing countries in $2016 .{ }^{9}$ Using actual country-level inward FDI stock and corporate tax rates (rather than the averaged ones as indicated in column F of Table 5) results in country-level estimates as presented in the first two columns of Table 9 in Appendix. These estimates use the same estimated coefficients for all countries and for the groups of developed and developing countries (in the second and third column, respectively). In our extended model, we use an even more granular level of fixed effects at the region-income group level to derive more precise estimates.

In the second part of the results section we turn to the results of our preferred, extended model. We begin with the regression results in Table 1 with two specifications that differ in their dependent variable: the overall rate of return versus only its equity component. In line with the hypotheses outlined above, we observe a statistically significant, negative relationship between the share of FDI from tax havens and the rate of return on FDI as well as its equity component. Importantly, the regressions in the extended model include controls for income, region and year

\footnotetext{
9 One speculative, and likely too optimistic, explanation for the lower parameter estimates is that recent government efforts to curb profit shifting have already started to have an impact and we can observe that change in the estimates. Also speculatively, because of the statistically insignificant coefficients for developed countries, we derive the estimate of $\$ 46$ billion of tax revenue losses for developed countries - this is to be interpreted with caution. If we combine it with the estimate for developing countries, a global estimate of \$129-\$141 billion is slightly lower than that of our first model, which used the same regression estimate for all countries.
} 
Table 1 Estimation results of the extended model. Source: Authors

(1)

Rate of return
(2)

Rate of returnequity component

$-0.123^{* * * *}$

(0.0178)

Omitted (=base)

0.0413

(0.132)

0.118

(0.137)

$-0.0659$

(0.143)

0.149

(0.137)

Omitted (=base)

$-0.0513$

(0.131)

0.0605

(0.132)

$-0.112$

(0.144)

0.212

(0.159)

$-0.0679$

(0.129)

$-0.250$

(0.212)

$0.0622 * * *$

(0.0176)

614

0.278

Yes

Yes

Yes

Standard errors clustered at region-income level in parentheses

$* * * p<0.01 ; * * p<0.05 ; * p<0.1$

fixed effects and interactions of the main explanatory variable, the share of FDI from tax havens, with dummy variables indicating the regional and income-group classifications, which are included both separately and simultaneously. The coefficient estimates of the negative relationship across these specifications are of similar magnitude and statistical significance, as shown in Table 6 in Appendix. While 


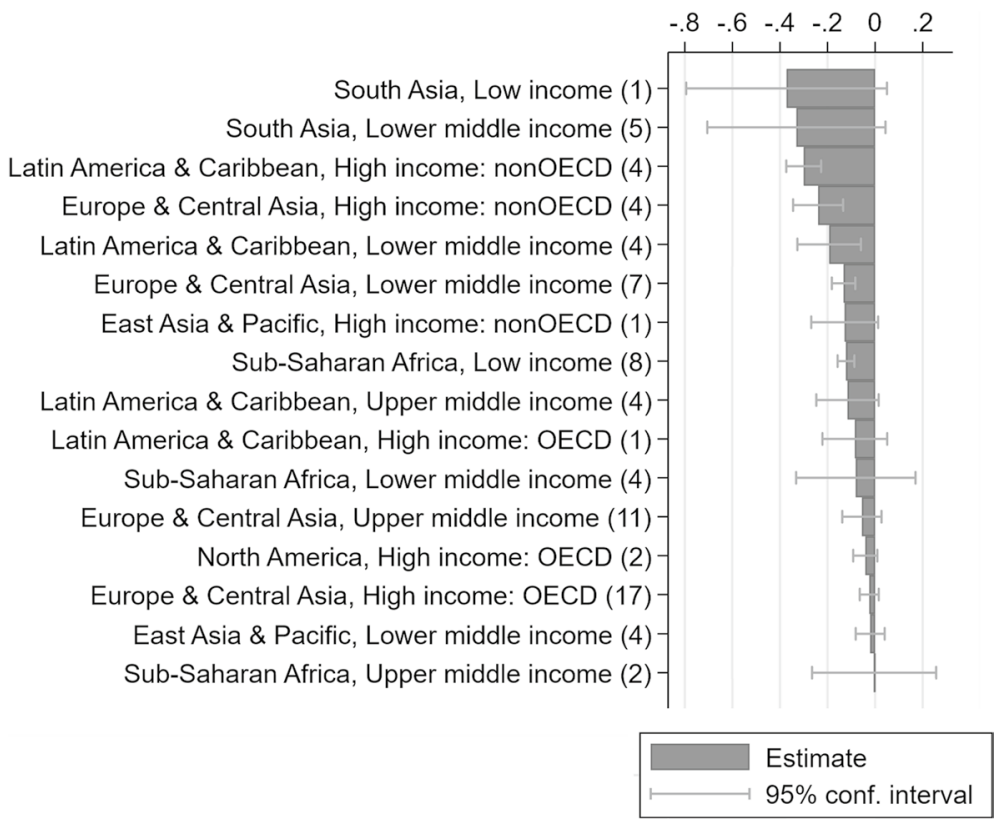

Fig. 1 Estimated coefficient of the relationship between the share of FDI from tax havens and the rate of return on FDI. Note: The number of countries in each region-income pair is in parentheses. Source: Authors

simultaneous inclusion of the two sets of interaction terms improves the explanatory power of the model, it could potentially lead to multicollinearity. We therefore use an $F$ test and find that the coefficients for both groups of the interaction terms are jointly statistically significant at the $1 \%$ level of significance. Also, as supporting evidence, we observe in Fig. 1 that the countries are distributed quite widely across income groups as well as regions, which is not consistent with the presence of multicollinearity. At the same time, it is important to highlight that none of the interaction terms is significant at the 5\% level of significance, which suggests that that there might not be large differences between countries from different income and regional groups. In our preferred specification we conservatively use standard errors clustered at the region-income group level, and we further report in Table 7 in Appendix the results of estimations that use robust standard errors and standard errors clustered at the country level, while keeping in mind the low heterogeneity in the explanatory variable over time which prevents a country fixed effects approach, as discussed above. Indeed, the standard confidence intervals associated with some of our estimates for individual region-income pairs are relatively large and our point estimates should thus be interpreted with caution.

Having established that the results are robust to the inclusion of the interaction terms and do not suffer from multicollinearity, our preferred extended model is the one with all interaction terms simultaneously included (shown in Table 1 and in column 3 of Table 6). The results of the estimation of this preferred extended model in the form of a summary of region-income group combinations are presented in 
Table 8 and in Fig. $1 .{ }^{10}$ In Fig. 1 as well as other figures we include estimates of $95 \%$ confidence intervals of the sums of the coefficients. ${ }^{11}$ These confidence intervals indicate the level of uncertainty of our estimates.

Our empirical approach is only suitable for estimating non-haven countries' revenue losses, rather than tax havens' revenue gains. Therefore, we exclude from further analysis the countries in those region-income groups for which the estimated parameter estimates are positive. ${ }^{12}$ Our extended approach takes advantage of the inclusion of region and income fixed effects and exploits the heterogeneity in the relationship between the rate of return and the share of FDI from tax havens across combinations of these classifications, thereby providing a more country-specific, and so more precise, estimate of the relationship for individual countries. Also, the negative relationship between the share of FDI from tax havens and the rate of return of FDI is fairly robust, with alternative classifications of tax havens yielding similar results. For example, it is statistically significant and negative for a list by Gravelle (2015) used by IMF's Crivelli et al. (2016). ${ }^{13}$ We now use these robust estimates of the relationship to estimate tax revenue losses.

To estimate tax revenue losses, we follow the steps as applied above for the baseline model, but with information specific to each country. In particular, we use country-specific information on FDI stock, exposure to FDI from tax havens and corporate tax rates. This contributes to the two sources of heterogeneity in the country-level estimates that we present below: across different region-income groups and across countries within each region-income group. First, the differentiated regression estimates contribute to the differences across countries from different

\footnotetext{
10 As an example, the estimate of -0.193 for Latin American lower-middle-income countries is a sum of the coefficients for the share of FDI from tax havens $(-0.123)$ and for the interaction terms with the lower-middle-income binary variable (0.0415) and the Latin American and Caribbean binary variable $(-0.112)$.

11 To estimate these confidence intervals, we calculate the standard errors of the combined distributions of the relevant estimated coefficients for each region-income group. We calculate the standard errors of the sum of the random variables, assumed to be normally distributed, using the standard formula (for the variance of the sum of three normally distributed random variables $X, Y$, and $Z)$ : $\operatorname{Var}(X+Y+Z)=\operatorname{Var}$ $(X)+\operatorname{Var}(Y)+\operatorname{Var}(Z)+2 * \operatorname{Cov}(X, Y)+2 * \operatorname{Cov}(Y, Z)+2 * \operatorname{Cov}(X, Z)$.

12 We recognise several potential reasons why we obtained positive parameter estimates for some country groups (which in the data include 13 countries). For example, our list of tax havens and SPE countries is the same for all countries, but in reality, each country's MNEs may use different tax havens with different intensity, resulting in an artificially deflated or inflated share of FDI from tax havens for such countries. A potential solution for future research might be to weigh the tax-haven FDI against a form of bilateral definition for tax havens, preferably defined as a continuous variable rather than a binary one. Alternatively, the data on bilateral FDI may be collected using different methodologies in different countries, as not all countries comply with the IMF's international standards for FDI reporting.

13 In principle, it would be possible to proxy the contribution of each tax haven to the revenue losses by estimating the regression with the independent variable of FDI share from one specific tax haven. In an exploratory analysis, we find that for many countries the variability of FDI data over such a short time period is not high enough for us to estimate the responsiveness of the rate of return on FDI to changes in the country of origin of FDI. Still, for some tax havens, especially those with good data coverage such as the Netherlands-the largest FDI investor according to the data-the estimated relationship is statistically significant and negative and it thus holds at individual origin-country level. Future research could examine these patterns to reveal which tax havens most contribute to the estimated revenue losses.
} 
income-region groups. Second, the differences in the estimated tax revenue losses across countries within the same income-region groups are driven by the heterogeneity in FDI stock, tax haven exposure and corporate tax rates. While Fig. 1 displays the first source of heterogeneity, Fig. 2 and other results below capture both sources of heterogeneity together. In total, we obtain estimates of tax revenue losses for 79 countries; this represents a comparatively good country coverage, in particular for developing countries.

We now put the aggregate estimates in macroeconomic perspective. If we sum up the 79 country-specific estimates for our preferred specification using the equity component of the rate of return, the total profits of MNEs that were shifted out of these 79 countries in 2016 amounted to $\$ 420$ billion, resulting in these countries incurring tax revenue losses of $\$ 125$ billion. We compare these estimates with relevant macroeconomic statistics from two sources. First, Tørsløv et al. (2018), ${ }^{14}$ report that the total corporate profits reported in the countries in our sample amounted to around $\$ 6340$ billion, implying that we estimate that around $6 \%$ of all corporate profits are shifted to tax havens. MNEs' profits from our 79 countries account for $\$ 1122$ billion, so this in turn implies that around 37\% of the MNEs' profits are shifted. Reported tax revenues in the 79 countries in our sample amount to approximately $\$ 1086$ billion annually, implying an estimate of around $10 \%$ of corporate tax revenue lost due to profit shifting. Second, for the subsamples of 53 and 66 countries for which data are available in the ICTD/UNU-WIDER's Government Revenue Dataset for corporate tax revenue and total tax revenue, respectively, our estimates imply that $8 \%$ of corporate tax revenue and $1 \%$ of total tax revenue is foregone. In terms of GDP, the shifted profits amount to close to $1 \%$, and around $0.25 \%$ of GDP is foregone in corporate tax revenue. We present estimates of shifted profits and corporate tax revenue losses for 79 individual countries in Table 9 in Appendix, also as shares of corporate profits, profits of MNEs, corporate tax revenue, total tax revenue, and GDP. Overall, our estimates' wide coverage-especially for low- and lower-middle-income countries - makes them particularly suitable for the study of the global distributional impact of international corporate profit shifting.

We compare estimated corporate tax revenue losses, relative to the countries' GDP and tax revenues, of country groups classified by income per capita. Figure 2 presents weighted averages for five income groups and seven regional groups classified by the World Bank. With the exception of the specific group of high-income non-OECD countries, ${ }^{15}$ the point estimates suggest that low- and

\footnotetext{
${ }^{14}$ We use the statistics from Tørsløv et al. (2018) only for comparison and presentational purposes. While Tørsløv et al. (2018) only report country-specific statistics on corporate profits, MNE profits, and corporate tax revenue for 28 out of the 79 countries in our sample, they also report an aggregate number for the rest of the world. From this number, in order to enable comparisons, we interpolate country-specific statistics using GDP, assuming that the share of GDP of each country within this group is equivalent to its share of corporate profits, MNE profits, and corporate tax revenue.

15 A relatively high weighted average for the group of 10 high-income non-OECD countries $(0.88 \%)$ is driven to a large extent by the result of one country, Russia, which we estimate foregoes $1.3 \%$ of its GDP through corporate tax revenue loss due to profit shifting. Indeed, without Russia, the weighted average for high-income non-OECD countries drops to a modest $0.39 \%$, which is below the weighted averages of both low-income and lower-middle-income countries.
} 

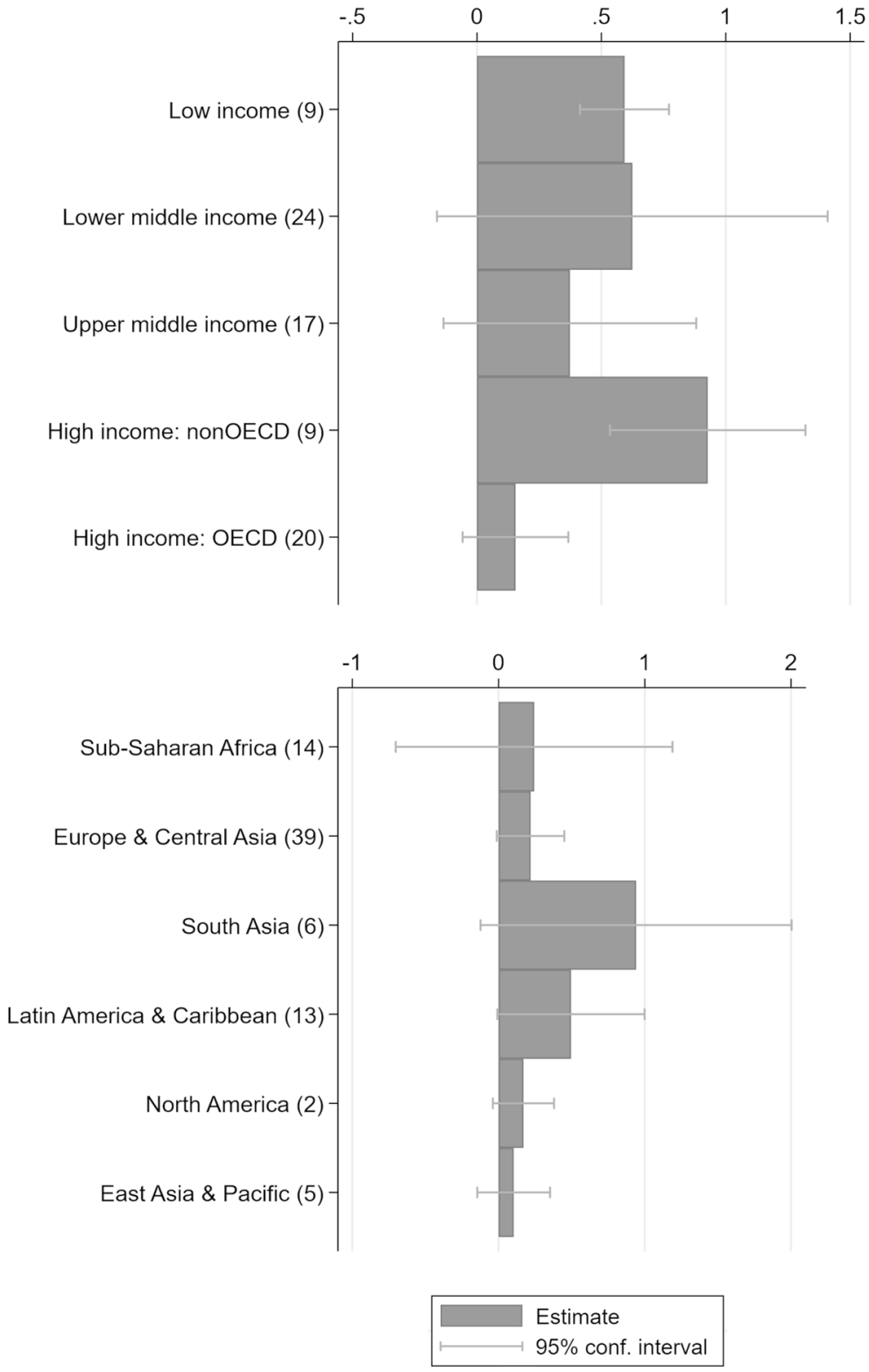

Fig. 2 Estimated tax revenue loss as a share of GDP, by income and region group, 2016. Note: The number of countries in each income or regional group is included in parentheses. Source: Authors

lower-middle-income countries lose more tax revenue as a share of their GDP than high-income OECD countries, but the confidence intervals are quite large and the differences between most income groups are not statistically significant. The exception of interest is the difference between the low-income and high-income OECD 
countries whose 95\% confidence intervals in Fig. 2 do not overlap. But generally, we find that there are almost no statistically significant differences across these groups.

In addition, we compare the point estimates for various groups of countries in Tables 10, 11, 12 and 13 in Appendix using a one-sided $t$ test for differences in simple averages of estimated tax revenue losses as a share of GDP and corporate tax revenue. In Table 10 we report that there is a statistically significant difference in the average point estimates for low- and lower-middle-income countries (around $0.6 \%$ of GDP) with respect to high-income OECD countries (around $0.15 \%$ GDP). Similar results hold for these estimates expressed as shares of corporate tax revenue-we estimate that low (lower middle)-income countries lose nearly 20 (12) percentage points more corporate tax revenue than high-income, OECD countries. We report these results for three alternative country groupings (an aggregated World Bank income classification, which uses only three low-middle-high-income groups instead of the original five, World Bank regional classification and UNCTAD development status classification) in Tables 11, 12 and 13, but conclude that, in general, the differences in the estimated tax revenue losses across groups of countries are mostly insignificant.

Figures 8, 9 and 10 in Appendix show the estimates of tax revenue losses as shares of GDP, shares of corporate tax revenue and total tax revenue, respectively, for all countries with available data, providing a clearer picture of which individual countries' losses contribute most to the aggregated numbers for income and regional groups that are displayed in Fig. $2 .^{16}$

In the final part of this section, we compare our estimates with those obtained by four other recent studies: Tørsløv et al. (2018), Cobham and Janský (2018, 2019a) and Clausing (2016). As we discuss in the related literature section above, these four studies use very different methodologies and data. While recognising the differences in empirical approaches and related difficulties, we make these comparisons to observe whether the inconsistent methodologies lead to similarly inconsistent results or not. We prefer to compare the estimates in relative terms, as we did for our main results discussed above, although we do provide a direct comparison in dollar values as well. ${ }^{17}$

\footnotetext{
16 We present the estimates of tax revenue losses here as shares of GDP because, in contrast to the other few suitable indicators for the relative size of the tax revenue losses such as total or corporate tax revenues, data on GDP is available for all countries in our sample. Generally, however, corporate tax revenues or total tax revenues are preferred to GDP for these comparisons; they would provide a more realistic perspective and better guidance from the tax revenue point of view, but their coverage is substantially worse than for GDP. Therefore, we believe that it is worth presenting the estimated losses in terms of the corporate tax revenues and total tax revenues, even if only for a subsample of countries. In Figures 8 , 9 and 10 and Table 9 in the Appendix we present our estimates at the country level as shares not only of GDP, but also of corporate tax revenue and total tax revenues, respectively, for all countries in our sample that have data on these tax revenues available for 2016 in the ICTD/UNU-WIDER's Government Revenue Dataset. The results show that significant shares of the countries' current tax revenues are relinquished due to profit shifting.

17 To analyse the disparities between the relative losses of different income groups, we compute the share of each income group on the total global estimated tax revenue losses resulting from profit shifting. Figures 11 and 12 show the share of the total shifted profits and total tax revenue losses, respectively, for each income group, as estimated by ours as well as the other four studies. Since these are absolute numbers, it is not surprising that losses in higher-income economies account for the bulk of global tax
} 
Each of the four studies provides estimates of MNE's profit shifting at the country level, but they differ in the extent to which they use extrapolations. Tørsløv et al. (2018) cover 37 countries at the country level and they estimate the total annual revenue loss of these countries at $\$ 165$ billion. In addition, they provide estimates for other countries in the form of the 'Rest of the world' group, reaching a total estimate of $\$ 185$ billion lost in tax revenue annually. Cobham and Janský (2018) provide estimates for the 102 countries for which they have data and for which they estimate their model. Cobham and Janský (2019a) only briefly discuss the extrapolation of their estimates to non-US-headquartered MNEs and prefer the sum of their countrylevel estimates. Clausing (2016) extends her US estimates to 24 other countries to cover $95 \%$ of the total profit share of Forbes Global 2000. In this paper's extended model, we carry out the estimation at income- and region-group level and then we apply these estimates at the individual country level for all 79 countries for which we have the underlying data. We then present results for the 79 countries and their sum only (in contrast, our baseline model estimates, similarly to those of UNCTAD 2015, are extrapolated to the rest of the world on the basis of FDI data). For the comparisons across studies below we use their estimates for individual countries, as detailed in Table 2, which summarises the number of individual countries covered, the total estimated tax revenue losses and their averages as shares of GDP for each of the five studies.

The total annual revenue losses estimated by the five compared studies are all in the lower hundreds of billions of US Dollars. Our estimate of \$125 billion is lower in magnitude than those reached by some of the comparison studies, which is in line with our estimates likely being lower-bound estimates. It is also within the oftencited range of \$100-\$240 billion reported by OECD's Johansson et al. (2017). The long-run results of Cobham and Janský (2018), whose estimates are quite rough, and those by Cobham and Janský (2019a), who present estimates only for US-headquartered MNEs and are thus narrower in their coverage, live up to their descriptions as overestimates of profit shifting, as we discussed in the related literature section above. We believe that the relatively lower estimate by Tørsløv et al. (2018), slightly higher than ours, is likely closer to the true scale of profit shifting, at least for the covered countries.

Differences across income groups are identified by every study, but the nature of these differences varies across the studies. Figure 3 compares the various studies' results by showing the estimated tax revenue losses as weighted shares of GDP for the five income groups used above and also includes, in parentheses, the number of countries per income group for each of the studies. In the first such comparison made, we find that, for example, for high-income OECD countries the estimates range from $0.15 \%$ of GDP in our results to around $0.54 \%$ of GDP in those by Clausing (2016). In theory, this might be driven by the differences in total revenue losses

Footnote 17 (continued)

revenue losses. Moreover, as indicated by the numbers in parentheses in the bar labels of Fig. 3, developing countries are strongly underrepresented in the samples of most of the abovementioned studies, a characteristic on which our results improve significantly. 
Table 2 A summary of the five studies estimating the scale of profit shifting. Source: Authors on the basis of the cited studies

\begin{tabular}{lccl}
\hline & $\begin{array}{l}\text { Number of } \\
\text { countries }\end{array}$ & $\begin{array}{l}\text { Total annual revenue loss of these } \\
\text { countries (USD billion) }\end{array}$ & $\begin{array}{l}\text { Average tax } \\
\text { revenue loss (\% } \\
\text { GDP) }\end{array}$ \\
\hline Our estimates & 79 & 125 & $0.26 \%$ \\
Tørsløv et al. (2018) & 37 & 165 & $0.26 \%$ \\
Cobham and Janský (2018) & 102 & $90 / 494 *$ & $0.15 \% / 0.81 \% *$ \\
Cobham and Janský (2019a) & 34 & 133 & $0.21 \%$ \\
Clausing (2016) & 25 & 280 & $0.48 \%$ \\
\hline
\end{tabular}

*For Cobham and Janský (2018) we present both their short run and long-run estimates. $\$ 90$ billion $(0.15 \%$ of GDP) is the short-run estimate, the long-run estimate amounts to $\$ 494$ billion $(0.81 \%$ of GDP). In this paper we use the short-run estimates as the preferred ones. See Cobham and Janský (2018) and our discussion in Sect. 2 and below for more details

discussed above, but in practice it is not because there are also substantial relative differences across studies. To generalise, we can divide the studies into two groups according to their high-level findings in terms of income groups. The three studies by Tørsløv et al. (2018), Cobham and Janský (2019a) and Clausing (2016) identify high-income OECD countries as those most affected by profit shifting, but that is also the group of countries by far most represented in these studies.

The results are different in the two studies with better country coverage. Our results as well as those by Cobham and Janský (2018) point to a similar pattern: that the tax revenues of low- and lower-middle-income countries are likely affected as much, and possibly more, as those of high-income OECD countries. For the results of Cobham and Janský (2018), in Fig. 3 we also include their long-run estimates which are approximately four times higher and are constructed to reflect the longrun effects of corporate tax base erosion. As discussed in Sect. 2, however, we argue that their short-run estimates are more comparable to the results of the other studies and we thus use only these in the subsequent figures.

Another way to look at the results is through Figs. 11 and 12, which show for each income group the share of the total profits shifted and the total tax revenue losses, respectively, as estimated by the studies. Since these are absolute numbers, it is not surprising that the higher-income economies' losses account for the bulk of global shifted profits and tax revenue losses. However, the two studies that do cover a number of low- and lower-middle-income countries suggest that these countries are indeed subject to significant profit shifting and incur large corporate tax revenue losses as a result. A similar picture is drawn by Figs. 13 and 14, which show the sums of the shifted profits and tax revenue losses for each income group as estimated by each of the five studies. In addition, we estimate correlation coefficients, although they are not very informative. ${ }^{18}$

\footnotetext{
${ }^{18} \mathrm{We}$ further analyse correlations between our results and the results in the four other papers and GDP per capita to shed more light on the relationship between countries' incomes and their estimated tax revenue losses resulting from profit shifting, and to compare our estimates more rigorously with those reported by similar studies. Table 16 in the Appendix reports the unweighted correlation coefficients for tax revenue losses as shares of GDP. The interpretation of the differences in the correlation coefficients
} 

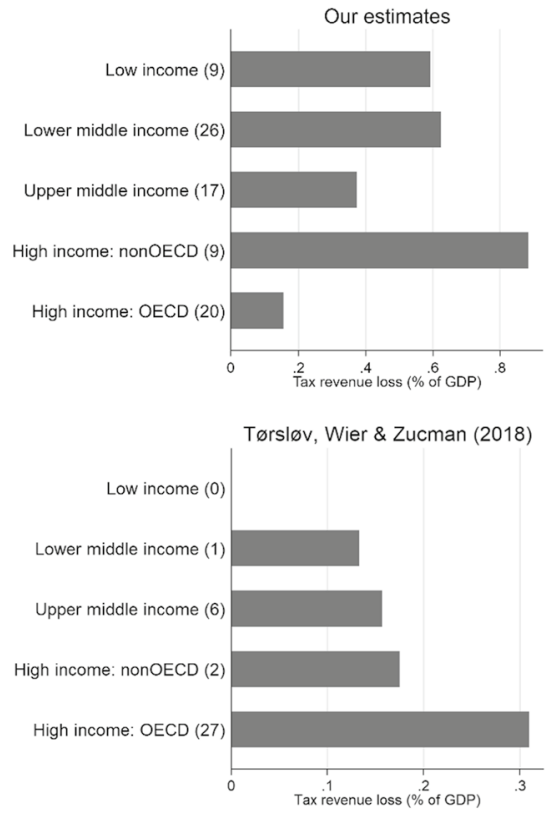

Cobham \& Janský (2019)

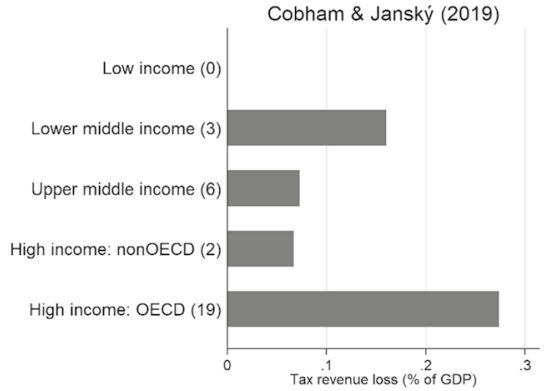

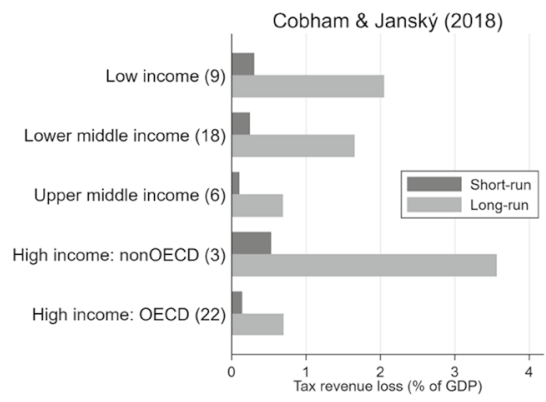

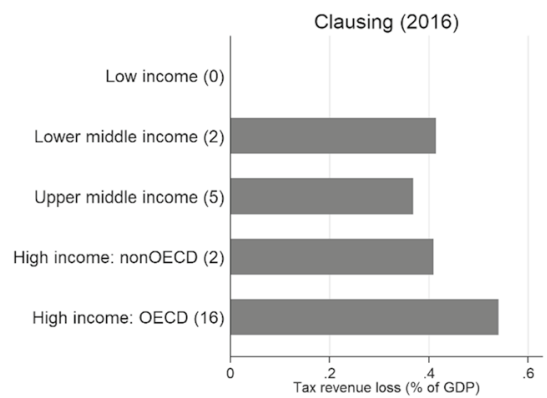

Fig. 3 Estimated tax revenue loss as a share of GDP_-weighted averages by income group, 2016. Note: The number of countries in each income group is included in parentheses. Source: Authors, data from Tørsløv et al. (2018), Cobham and Janský (2018), Cobham and Janský (2019a), and Clausing (2016)

Due to large differences in the coverage of countries, especially in some income groups, we also compare the results of the five studies using only common subsamples of covered countries. Figure 4 shows individual comparisons of our results with each of the other four studies, again with the numbers of countries that are covered by these pairs of studies in parentheses. In general, our estimates are lower for developed countries and higher for developing countries. Unfortunately, only eight countries (six of which are high-income OECD countries) lie at the intersection of the

Footnote 18 (continued)

is complicated due to the substantial differences in country coverage, which we discuss in the main text. Overall, the estimated correlation coefficients vary across the five studies, and most of the correlation coefficients are not different from zero at the standard levels of statistical significance. 

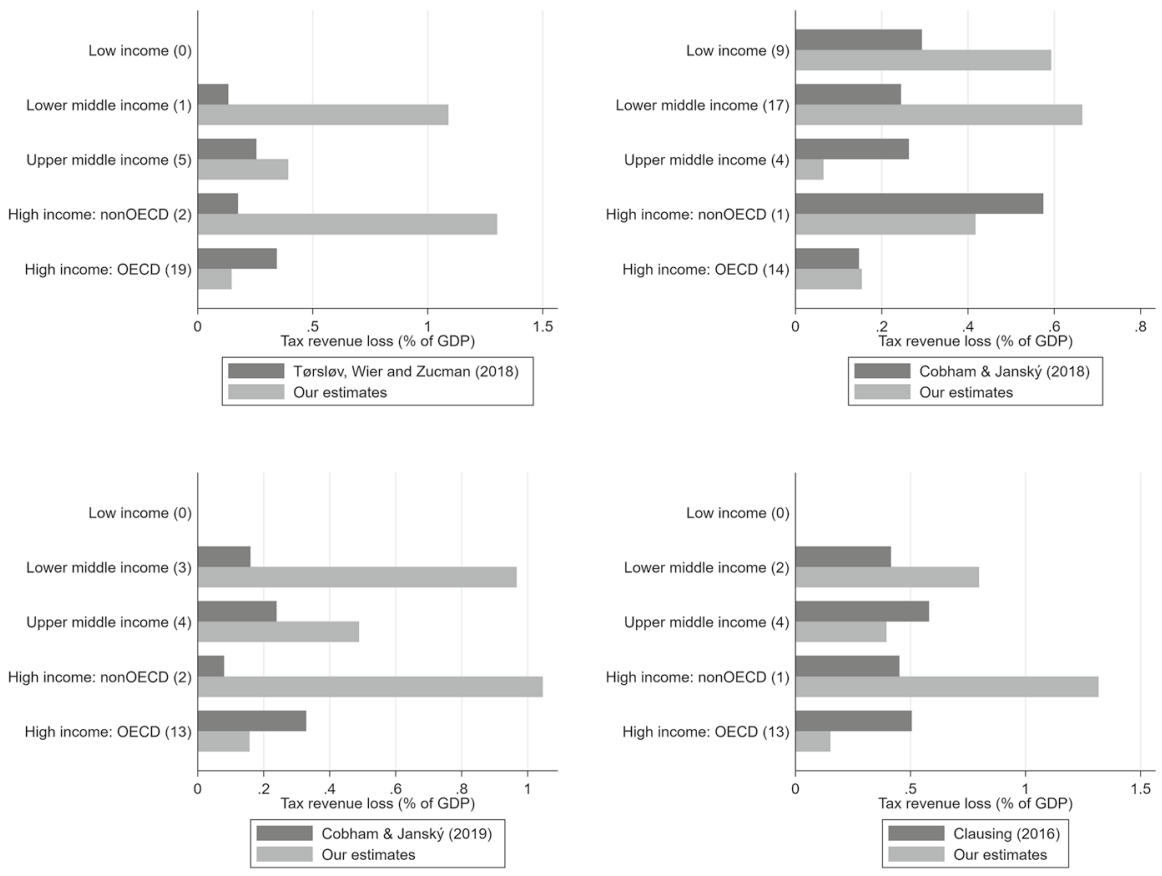

Fig. 4 Total estimated tax revenue losses by income group, pairwise-consistent samples, 2016. Note: The number of countries in each income group is included in parentheses Source: Authors; data from Tørsl $\varnothing \mathrm{v}$ et al. (2018), Cobham and Janský (2018, 2019a), and Clausing (2016)

samples of all the five studies, allowing a single direct comparison of the results of the five studies. The revenue losses of these eight countries as estimated by the compared studies are presented in Fig. 5, but the studies seem to differ for this common sample as much as in their overall findings presented above.

We now discuss the likely reasons why there are differences between the studies. The various differences between this and the other four studies are difficult to reconcile and we argue that there are two main reasons behind this. First and foremost, the methodologies used in the five studies are very different and some of them, such as Cobham and Janský (2018), are not very reliable, as we discussed in the related literature section. Second, there are important differences in the overall coverage of countries per study-ours covers 79, while Tørsløv et al. (2018) cover 37, Cobham and Janský (2018) 102, Cobham and Janský (2019a) 30, and Clausing (2016) 25. Importantly, the number of countries included in the individual income groups varies greatly. For example, neither Tørsløv et al. (2018), nor Cobham and Janský (2019a), nor Clausing (2016) have any low-income countries in their sample and only a few lower-middleincome countries $(1,3$, and 2 , respectively), while our paper, as well as that by Cobham and Janský (2018), have a relatively good coverage of low (9 and 24, respectively) and lower-middle-income countries (24 and 29). Tables 14 and 15 provide a more detailed look at each study's coverage of countries and the economic activity measured by GDP in each income group. 


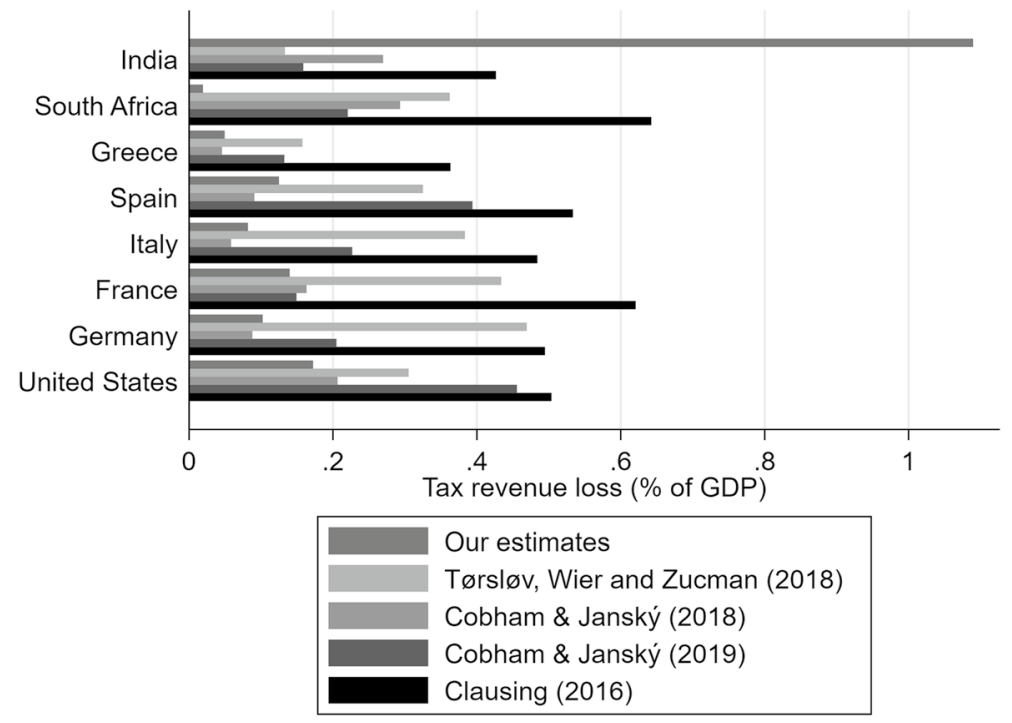

Fig. 5 Estimated tax revenue losses-one consistent sample across all studies, 2016. Source: Authors; data from Tørsløv et al. (2018), Cobham and Janský (2018, 2019a), and Clausing (2016)

\section{Conclusion}

In this paper, we have focused on quantifying the scale of profit shifting by MNEs and the resulting corporate tax revenue losses, using FDI data. We recognise the contribution of this work to the existing literature in the following five aspects. First, we have followed the so-called FDI approach, one of the leading methodological approaches to estimating the scale of profit shifting as pioneered by UNCTAD (2015), in what we call the baseline model, using new data to obtain updated estimates and confirming the robustness of the approach. Second, we have developed an extended model which innovates on the baseline model in a number of ways and has enabled us to obtain detailed estimates of the scale of profit shifting. Our preferred extended model estimates annual tax revenue lost by the 79 countries in our sample due to profit shifting at $\$ 125$ billion. Third, we have used the extended model to arrive at tax revenue loss estimates. We provide estimates for a wide range of countries, including a number of developing ones. We find that while OECD countries lose the least, low- and lowermiddle-income countries lose the most corporate tax revenue both relative to their GDP and relative to their corporate and total tax revenue. Fourth, we have compared our results with four other existing studies. Fifth, we have used our and other studies' estimates to observe differences in how various countries' government revenues are affected by profit shifting. All the existing studies identify differences across income groups, but the nature of these differences varies across the five studies.

We find, using our new estimates, that profit shifting and associated tax revenue losses are relatively high in most studied countries and across most income groups. At the same time, low-income countries are more likely to be among those that are relatively less able to implement effective tools to reduce the amount of profit 
shifted out of their countries. In terms of policy recommendations, our work thus further corroborates the importance of the wider inclusiveness of initiatives such as the OECD's Base Erosion and Profit Shifting framework for the tax revenues that developing countries need. Our estimates might also assist policy makers in developing countries for which country-specific estimates of profit shifting scale were previously hard to come by. More generally, we provide estimates of the vulnerability to profit shifting for individual countries, and policy makers should pay close attention to their countries' specific situations.

We contribute to the existing literature with improved estimates of the scale of profit shifting using FDI data. Since the data do not enable us to precisely quantify the various biases of our estimates, as we have discussed, our estimates are only illustrative. In addition to addressing these limitations, future research should further develop the empirical approach to reveal which havens are responsible for the estimated revenue losses. One promising source is the MNE country-by-country reporting data to be published in aggregate and anonymised form in 2019 (OECD 2018). However, only once these data have been made publicly available in full and detailed form will researchers and policy makers find a comprehensive answer to what the true scale of profit shifting is.

Acknowledgements This research was supported by the European Union's Horizon 2020 program through the COFFERS Project (No. 727145). We also gratefully acknowledge support from the Grant Agency of the Czech Republic (P403/18-21011S) and the Charles University Grant Agency (848517). We wish to thank the editor and two anonymous referees for their excellent comments. We are grateful to Bruno Casella, Kim Clausing, Alex Cobham, Caroline Schimanski and conference and seminar participants at UNU-WIDER, the International Institute of Public Finance, the University of Lisbon, the University of Oslo, University of Auckland and Charles University for comments.

The opinions expressed in this article are those of the authors and do not necessarily reflect the views of the UNU-WIDER, its Board of Directors, or the countries they represent.

Open Access This article is licensed under the terms of the Creative Commons Attribution-NonCommercial-ShareAlike 3.0 IGO License, which permits any non-commercial use, sharing, adaptation, distribution and reproduction in any medium or format, as long as you give appropriate credit to the UNU-WIDER, provide a link to the Creative Commons licence, and indicate if changes were made. If you remix, transform, or build upon this article or a part thereof, you must distribute your contributions under the same licence as the original.

The use of the UNU-WIDER's name, and the use of the UNU-WIDER's logo, shall be subject to a separate written licence agreement between the UNU-WIDER and the user and is not authorized as part of this CC-IGO licence. Note that the link provided above includes additional terms and conditions of the licence.

The images or other third party material in this article are included in the article's Creative Commons licence, unless indicated otherwise in a credit line to the material. If material is not included in the article's Creative Commons licence and your intended use is not permitted by statutory regulation or exceeds the permitted use, you will need to obtain permission directly from the copyright holder.

To view a copy of this licence, visit http://creativecommons.org/licenses/by-nc-sa/3.0/igo/.

\section{Appendix}

See Figs. 6, 7, 8, 9, 10, 11, 12, 13 and 14.

See Tables 3, 4, 5, 6, 7, 8, 9, 10, 11, 12, 13, 14, 15, 16. 


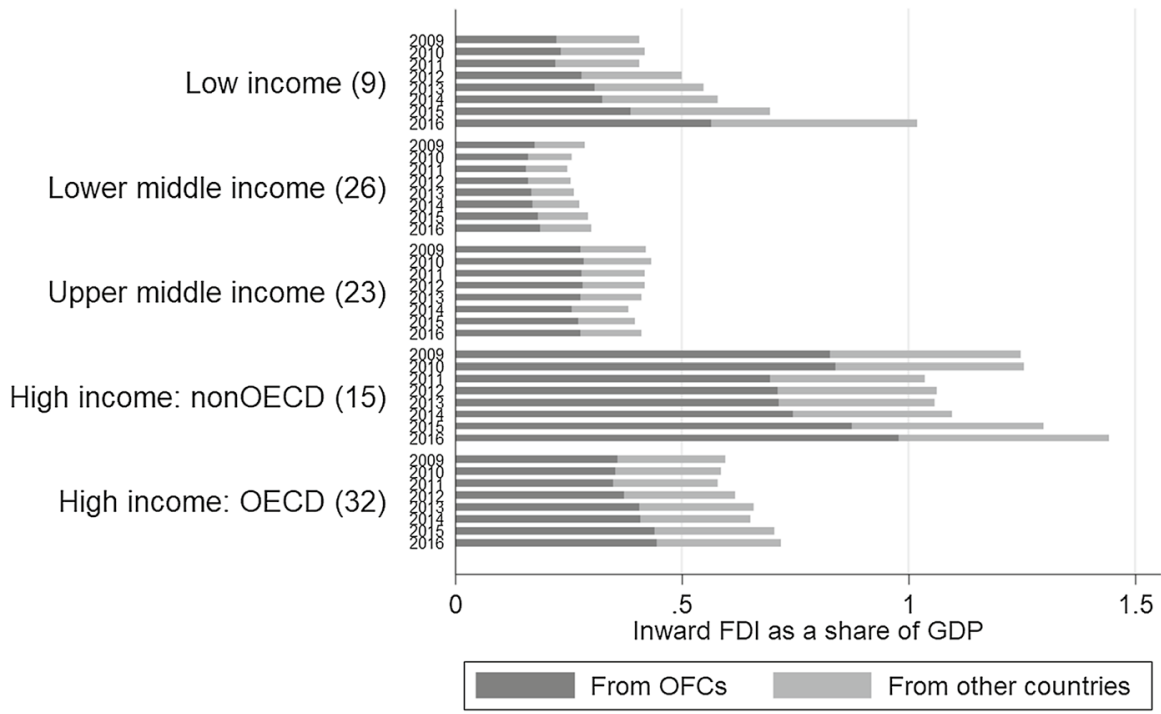

Fig. 6 Development of the volume of total inward FDI stock between 2009 and 2016 (as a share of GDP; by income group and origin). Note: The classification of 'offshore financial centres' is defined in Sect. 4. The number of countries in each income group in the data for the year 2016 is included in parentheses. Source: Data from IMF's CDIS; classification by the World Bank; authors' construction.

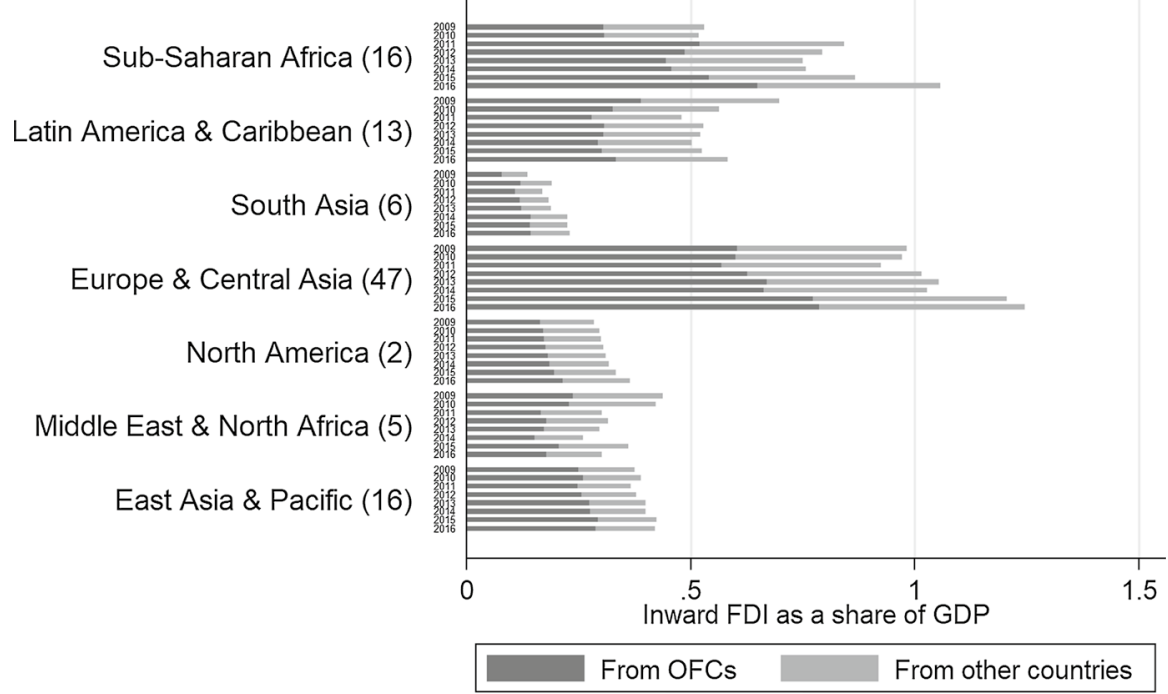

Fig. 7 Development of the volume of total FDI stock between 2009 and 2016 (by region and origin). Note: The classification of 'offshore financial centres' is defined in Sect. 4. The number of countries in each regional group in the data for the year 2016 is included in parentheses. Source: Data from IMF's CDIS; classification by the World Bank; authors' construction 


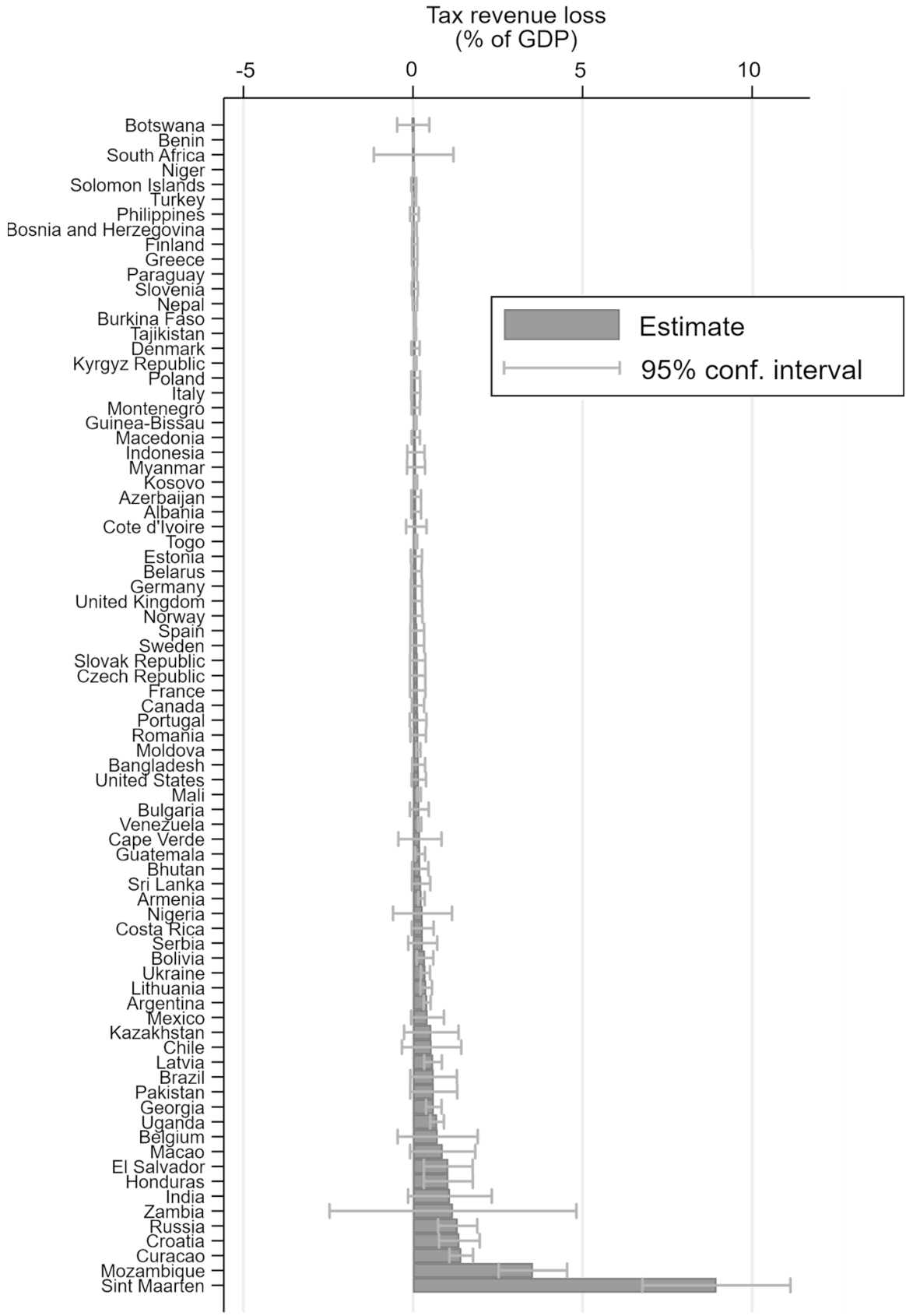

Fig. 8 Estimated tax revenue loss as a share of GDP, 2016. Source: Authors, data on GDP from the World Bank, the United Nations, and the CIA World Factbook 


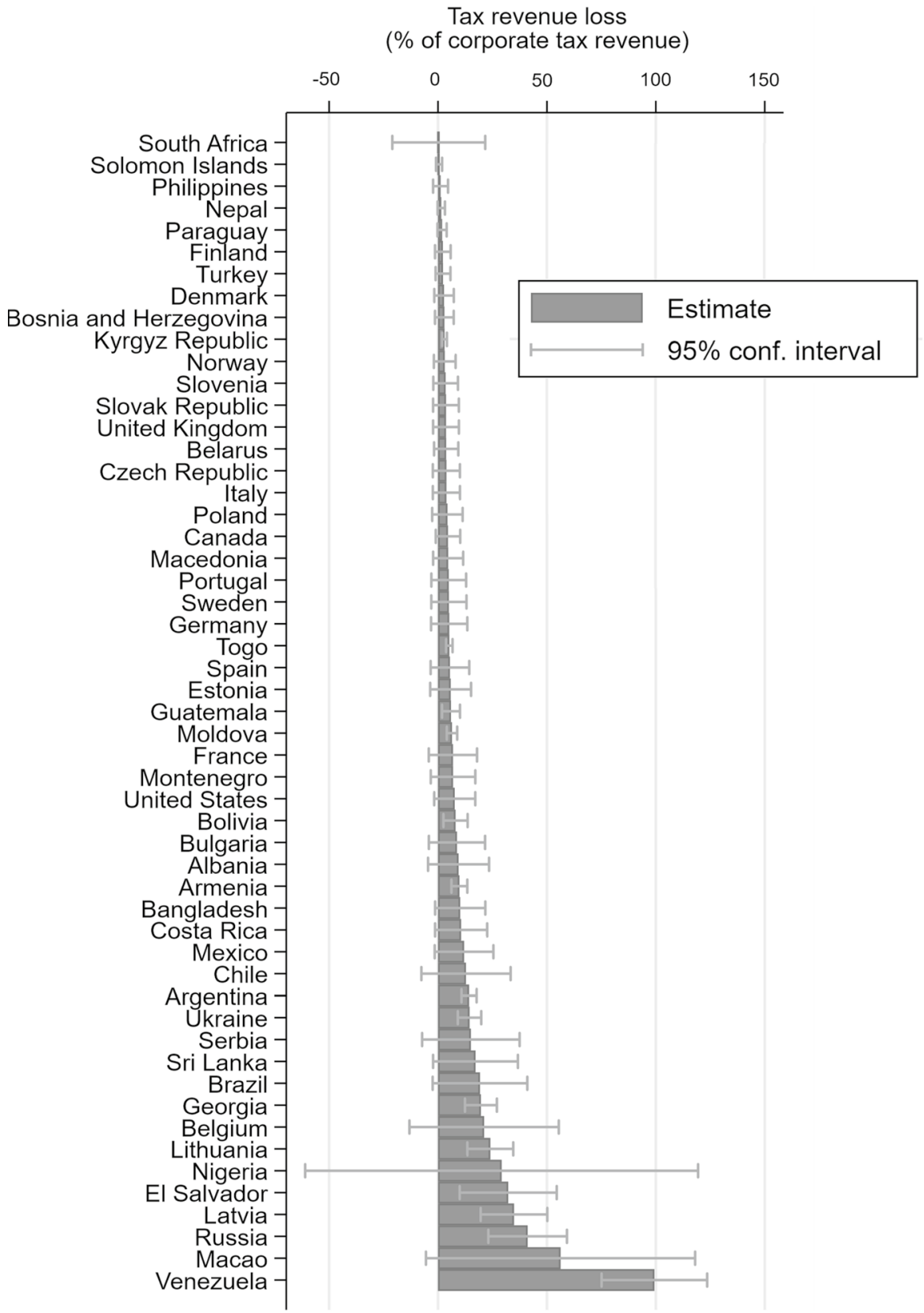

Fig. 9 Share of estimated tax revenue losses on corporate tax revenue, 2016. Source: Authors, data on corporate tax revenue from the Government Revenue Dataset 


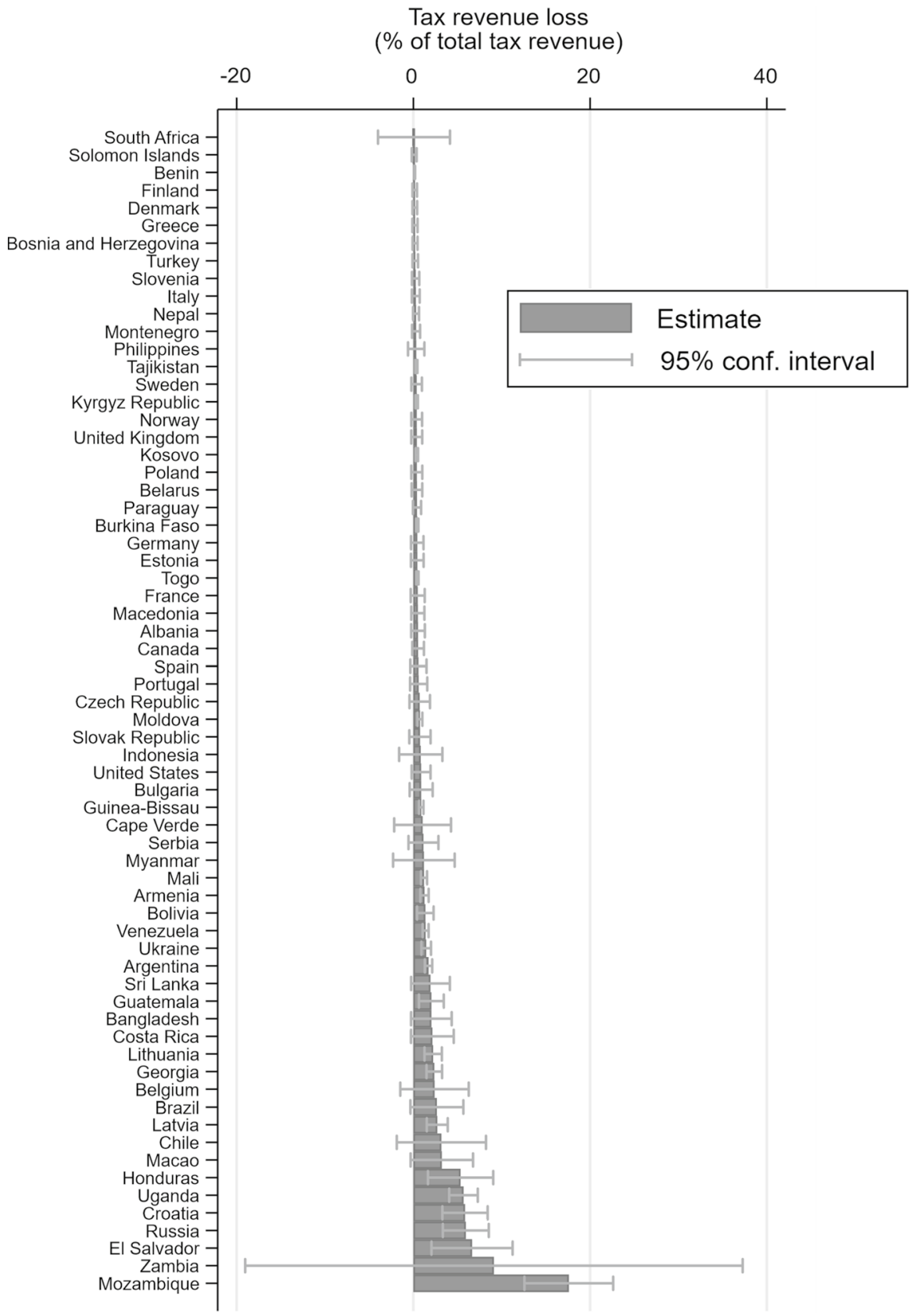

Fig. 10 Share of estimated tax revenue losses on total tax revenue, 2016. Source: Authors, data on tax revenue from the Government Revenue Dataset 


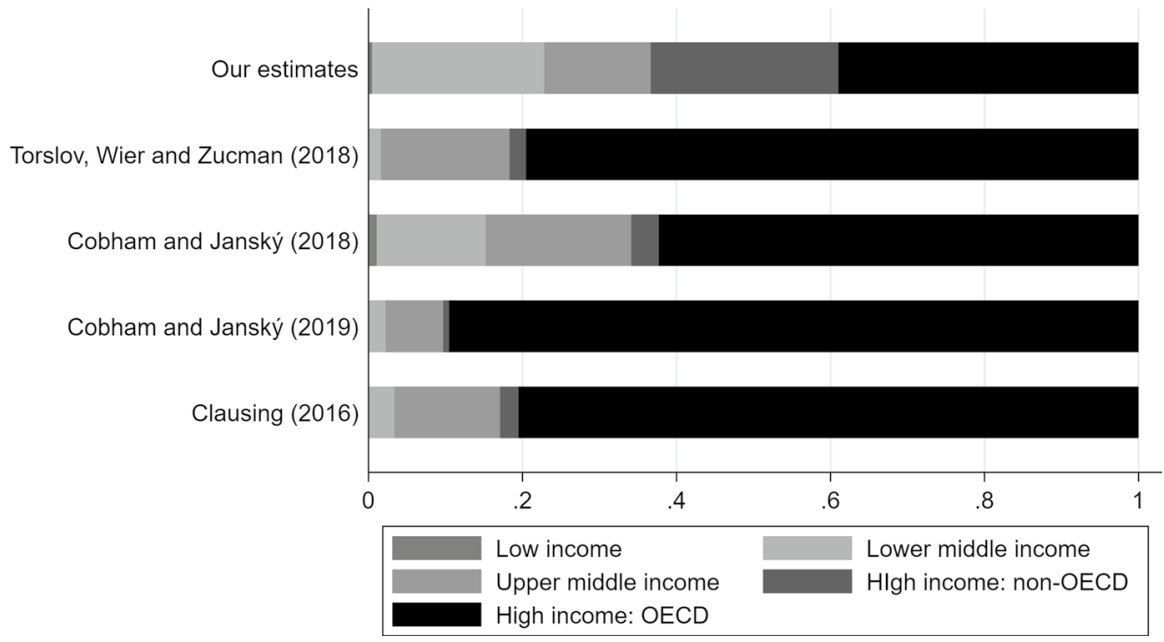

Fig. 11 Share of shifted profits on total global shifted profits, by income group, 2016. Source: Authors; data from Tørsløv et al. (2018), Cobham and Janský (2018, 2019a), and Clausing (2016)

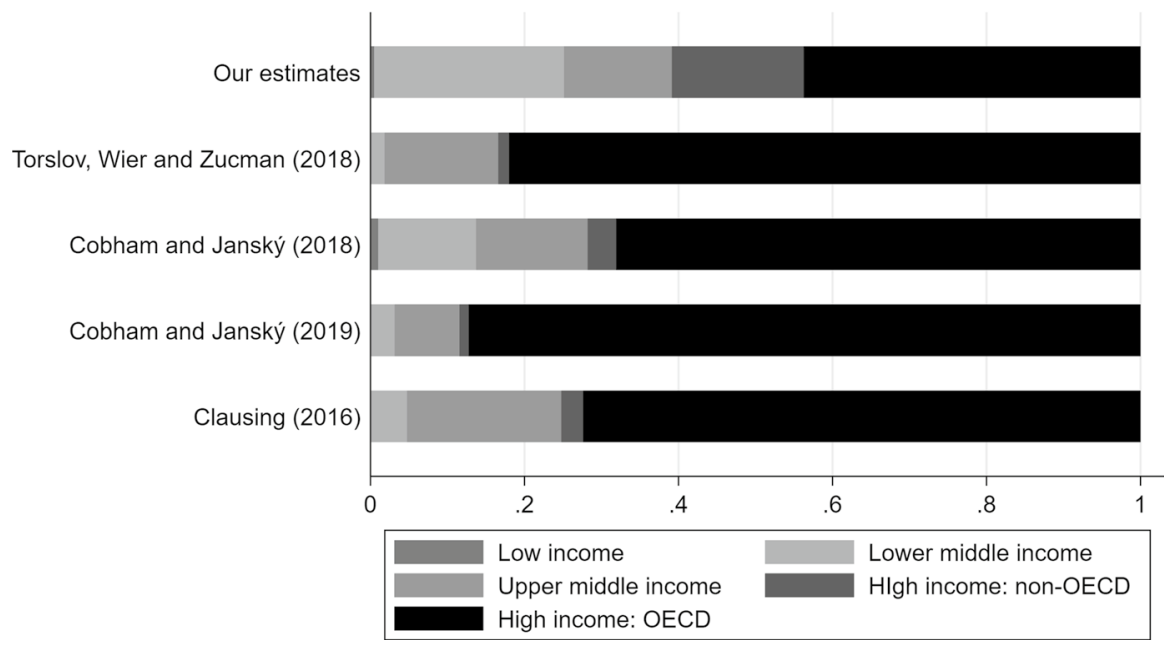

Fig. 12 Share of estimated tax revenue losses on total global estimated revenue losses, by income group, 2016. Source: Authors; data from Tørsløv et al. (2018), Cobham and Janský (2018, 2019a), and Clausing (2016) 

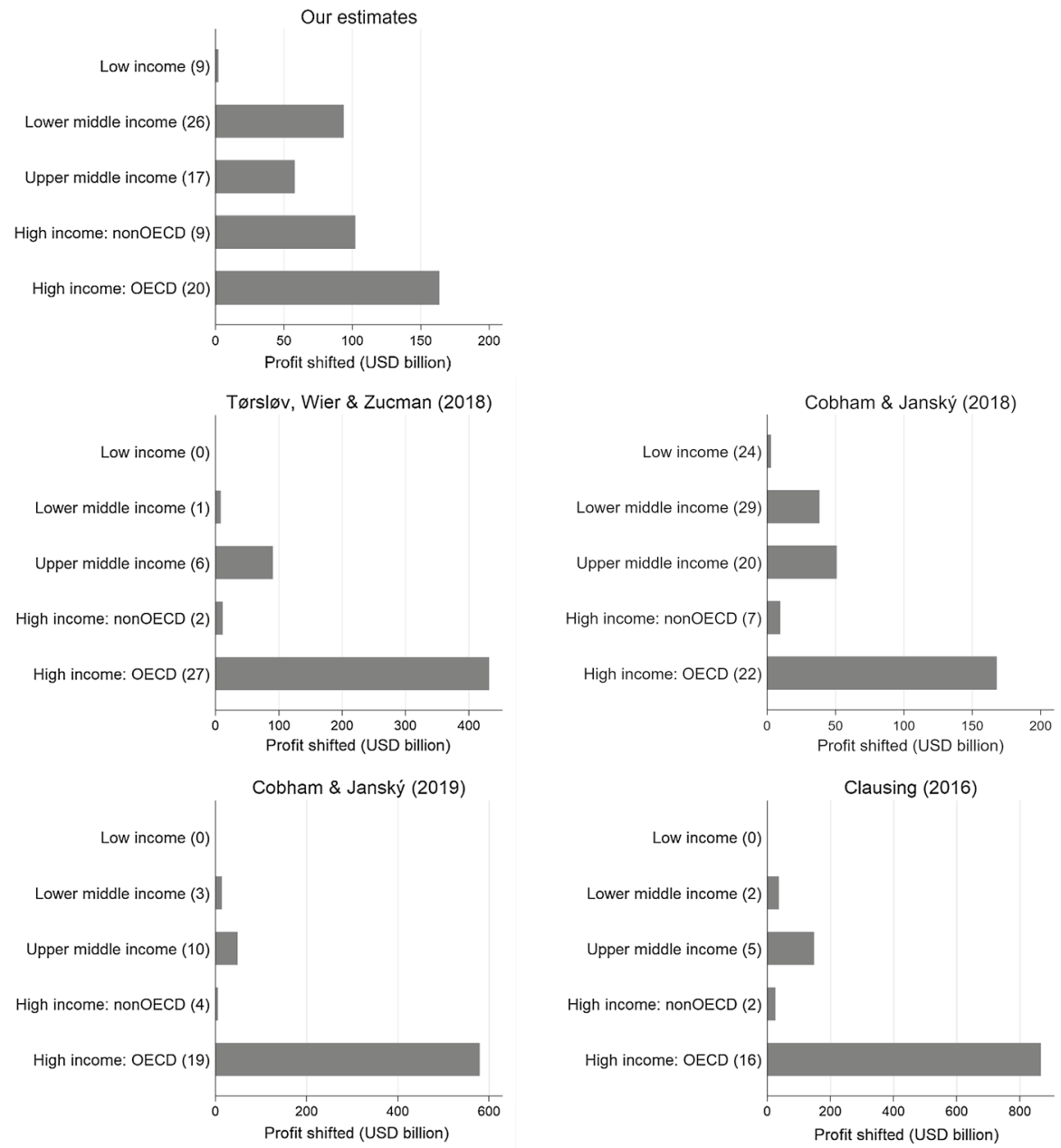

Fig. 13 Total estimated profit shifted out of countries by income group, 2016. Note: The number of countries in each income group is included in parentheses. Source: Authors; data from Tørsløv et al. (2018), Cobham and Janský (2018, 2019a), and Clausing (2016) 

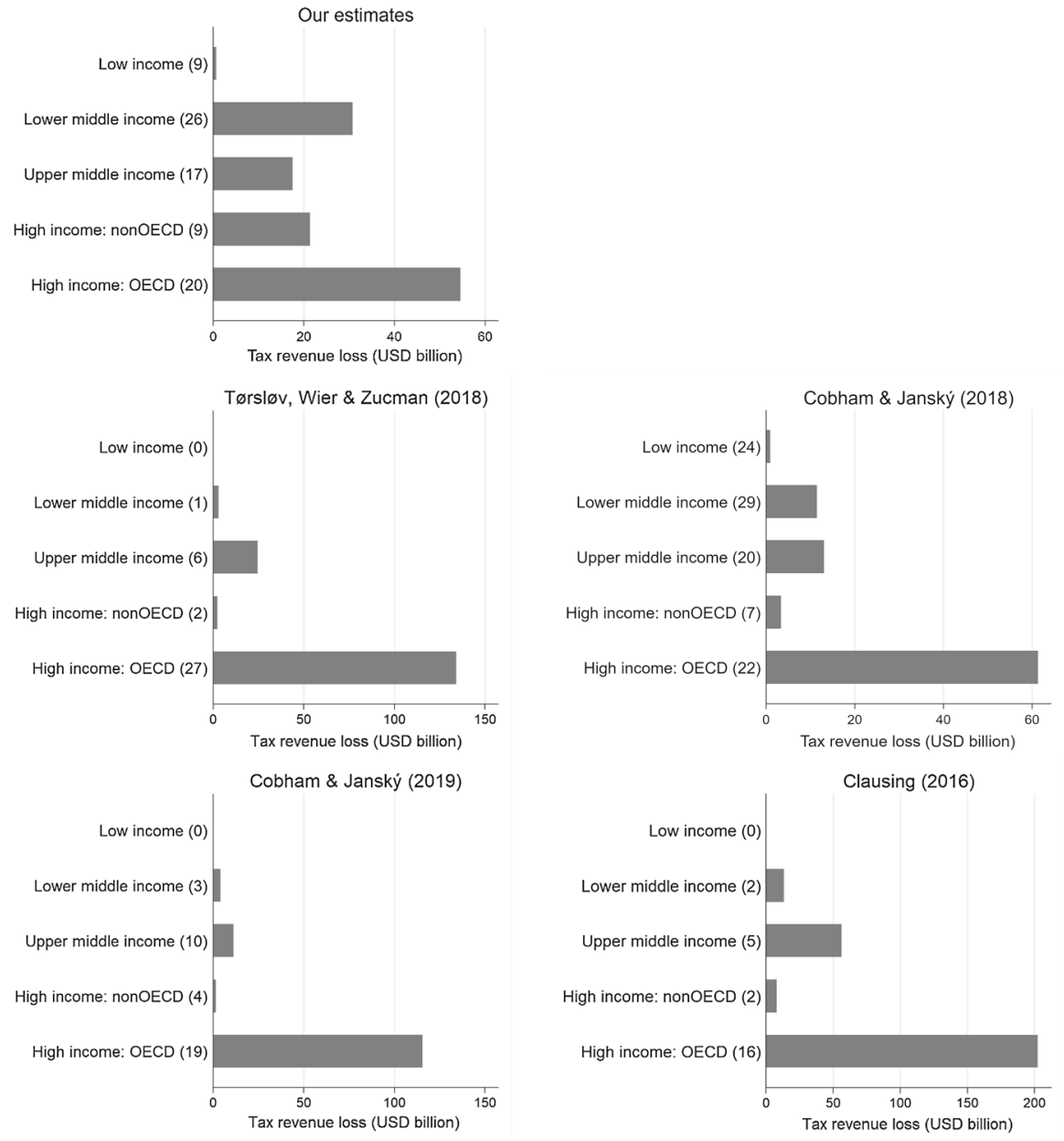

Fig. 14 Total estimated tax revenue losses by income group, 2016. Note: The number of countries in each income group is included in parentheses Source: Authors; data from Tørsløv et al. (2018), Cobham and Janský (2018, 2019a), and Clausing (2016) 
Table 3 Summary statistics of the used variables. Source: Authors; data from IMF's CDIS and UNCTAD's FDI database

\begin{tabular}{|c|c|c|c|c|c|c|}
\hline Variable & Count & Mean & SD & Min & Max & Source \\
\hline Rate of return on FDI (\%) & 631 & 8.25 & 5.52 & 0.06 & 38.88 & IMF BoP \\
\hline $\begin{array}{l}\text { Rate of return on FDI-equity } \\
\text { component }(\%)\end{array}$ & 614 & 7.60 & 5.55 & 0 & 37.64 & IMF BoP \\
\hline $\begin{array}{l}\text { Rate of return on FDI-debt } \\
\text { component }(\%)\end{array}$ & 542 & 0.72 & 0.77 & 0 & 6.97 & IMF BoP \\
\hline Share of FDI from tax havens & 631 & 0.2803 & 0.1329 & 0 & 0.701 & IMF CDIS \\
\hline Inward FDI stock (USD billion) & 631 & $157,512.9$ & $375,594.7$ & 132.16 & $3,711,057$ & IMF CDIS \\
\hline GDP (USD billion) & 628 & $669,165.9$ & $2,020,984$ & 245.56 & $18,600,000$ & WB, UN, CIA \\
\hline Nominal corporate tax rate $(\%)$ & 631 & 23.45 & 8.37 & 0 & 40.69 & KPMG, WB \\
\hline $\begin{array}{l}\text { Total corporate tax revenue ( } \% \text { of } \\
\text { GDP)* }\end{array}$ & 66 & 21.06 & 6.83 & 7.63 & 45.88 & GRD \\
\hline Total tax revenue (\% of GDP)* & 53 & 2.58 & 1.05 & 0.20 & 5.50 & GRD \\
\hline
\end{tabular}

*This data is for 2016 only; in our analysis, it is used only to present results 


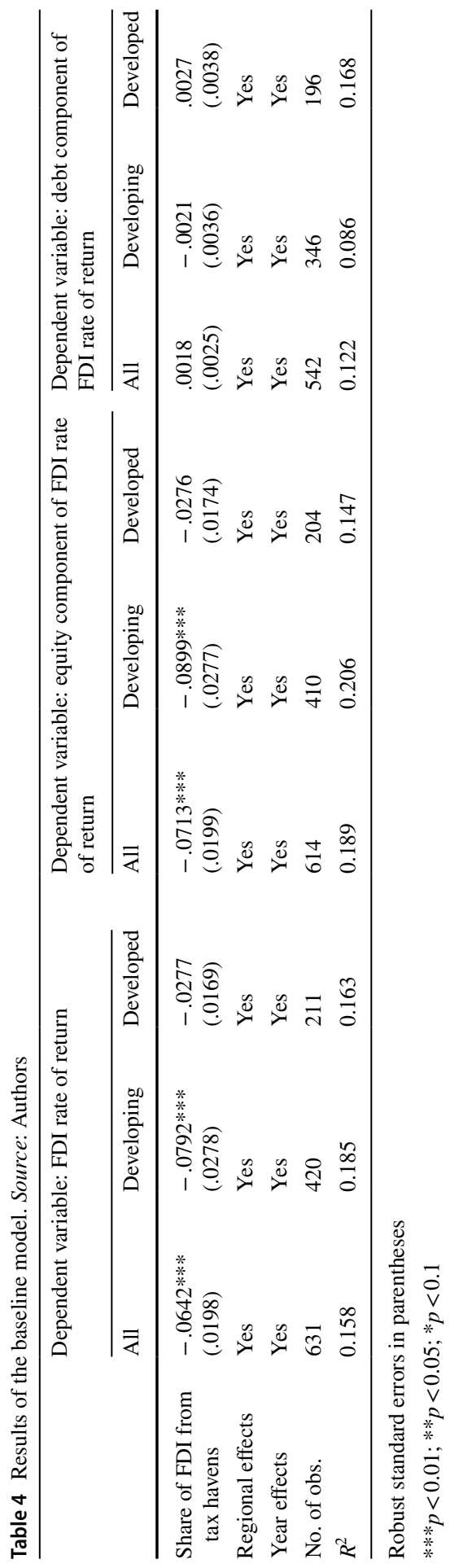




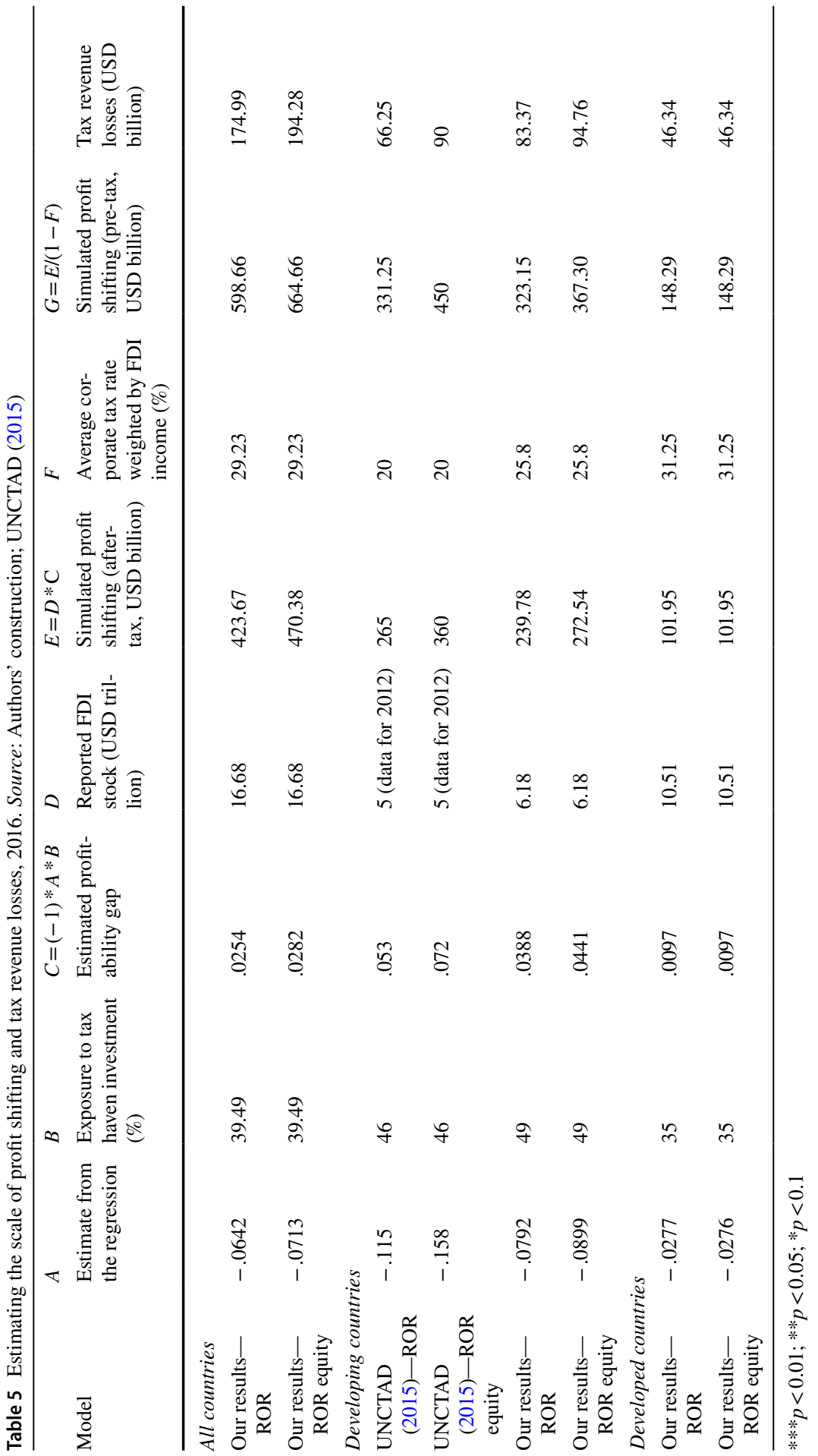


Table 6 Sensitivity analysis of the inclusion of interaction terms in the extended model. Source: Authors

\begin{tabular}{|c|c|c|c|}
\hline & $\begin{array}{l}\text { (1) } \\
\text { ROR-equity compo- } \\
\text { nent }\end{array}$ & $\begin{array}{l}\text { (2) } \\
\text { ROR-equity compo- } \\
\text { nent }\end{array}$ & $\begin{array}{l}\text { (3) } \\
\text { ROR_equity component }\end{array}$ \\
\hline $\begin{array}{l}\text { Share of FDI from tax } \\
\text { havens (Share) }\end{array}$ & $\begin{array}{l}-0.112 * * * \\
(0.0391)\end{array}$ & $\begin{array}{l}-0.128 * * * \\
(0.0115)\end{array}$ & $\begin{array}{l}-0.123 * * * \\
(0.0178)\end{array}$ \\
\hline Share * low income & & Omitted (= base) & Omitted (= base) \\
\hline $\begin{array}{l}\text { Share }{ }^{*} \text { lower middle } \\
\text { income }\end{array}$ & & $\begin{array}{l}0.0463 \\
(0.0669)\end{array}$ & $\begin{array}{l}0.0413 \\
(0.132)\end{array}$ \\
\hline $\begin{array}{l}\text { Share * upper middle } \\
\text { income }\end{array}$ & & $\begin{array}{l}0.1000 * \\
(0.0562)\end{array}$ & $\begin{array}{l}0.118 \\
(0.137)\end{array}$ \\
\hline $\begin{array}{l}\text { Share }{ }^{*} \text { high income: } \\
\text { non-OECD }\end{array}$ & & $\begin{array}{l}-0.134 * * \\
(0.0643)\end{array}$ & $\begin{array}{l}-0.0659 \\
(0.143)\end{array}$ \\
\hline $\begin{array}{l}\text { Share }{ }^{*} \text { high income: } \\
\text { OECD }\end{array}$ & & $\begin{array}{l}0.139 * * * \\
(0.0483)\end{array}$ & $\begin{array}{l}0.149 \\
(0.137)\end{array}$ \\
\hline $\begin{array}{l}\text { Share * sub-Saharan } \\
\text { Africa }\end{array}$ & Omitted (= base) & & Omitted (= base) \\
\hline $\begin{array}{l}\text { Share* Europe and } \\
\text { Central Asia }\end{array}$ & $\begin{array}{l}0.0366 \\
(0.0452)\end{array}$ & & $\begin{array}{l}-0.0513 \\
(0.131)\end{array}$ \\
\hline $\begin{array}{l}\text { Share * East Asia and } \\
\text { Pacific }\end{array}$ & $\begin{array}{l}0.134 * * \\
(0.0545)\end{array}$ & & $\begin{array}{l}0.0605 \\
(0.132)\end{array}$ \\
\hline $\begin{array}{l}\text { Share * Latin America } \\
\text { and Caribbean }\end{array}$ & $\begin{array}{l}-0.104 \\
(0.0958)\end{array}$ & & $\begin{array}{l}-0.112 \\
(0.144)\end{array}$ \\
\hline $\begin{array}{l}\text { Share } * \text { Middle East and } \\
\text { North Africa }\end{array}$ & $\begin{array}{l}0.269 * * \\
(0.104)\end{array}$ & & $\begin{array}{l}0.212 \\
(0.159)\end{array}$ \\
\hline Share * North America & $\begin{array}{l}0.0670 \\
(0.0412)\end{array}$ & & $\begin{array}{l}-0.0679 \\
(0.129)\end{array}$ \\
\hline Share * South Asia & $\begin{array}{l}-0.228 \\
(0.182)\end{array}$ & & $\begin{array}{l}-0.250 \\
(0.212)\end{array}$ \\
\hline Constant & $\begin{array}{l}0.0787 * * * \\
(0.0195)\end{array}$ & $\begin{array}{l}0.0843 * * * \\
(0.0175)\end{array}$ & $\begin{array}{l}0.0622 * * * \\
(0.0176)\end{array}$ \\
\hline Observations & 614 & 614 & 614 \\
\hline$R^{2}$ & 0.264 & 0.230 & 0.278 \\
\hline Income effects & Yes & Yes & Yes \\
\hline Regional effects & Yes & Yes & Yes \\
\hline Year effects & Yes & Yes & Yes \\
\hline $\begin{array}{l}F \text { test for joint sig- } \\
\text { nificance of regional } \\
\text { group interactions, } p \\
\text { value in brackets }\end{array}$ & $\begin{array}{l}46.20 \\
{[0]}\end{array}$ & & $\begin{array}{l}54.18 \\
{[0]}\end{array}$ \\
\hline $\begin{array}{l}F \text { test for joint signifi- } \\
\text { cance of income group } \\
\text { interactions, } p \text { value in } \\
\text { brackets }\end{array}$ & & $\begin{array}{l}23.45 \\
{[0]}\end{array}$ & $\begin{array}{l}19.45 \\
{[0]}\end{array}$ \\
\hline
\end{tabular}

Standard errors in parentheses

$* * * p<0.01 ; * * p<0.05 ; * p<0.1$ 


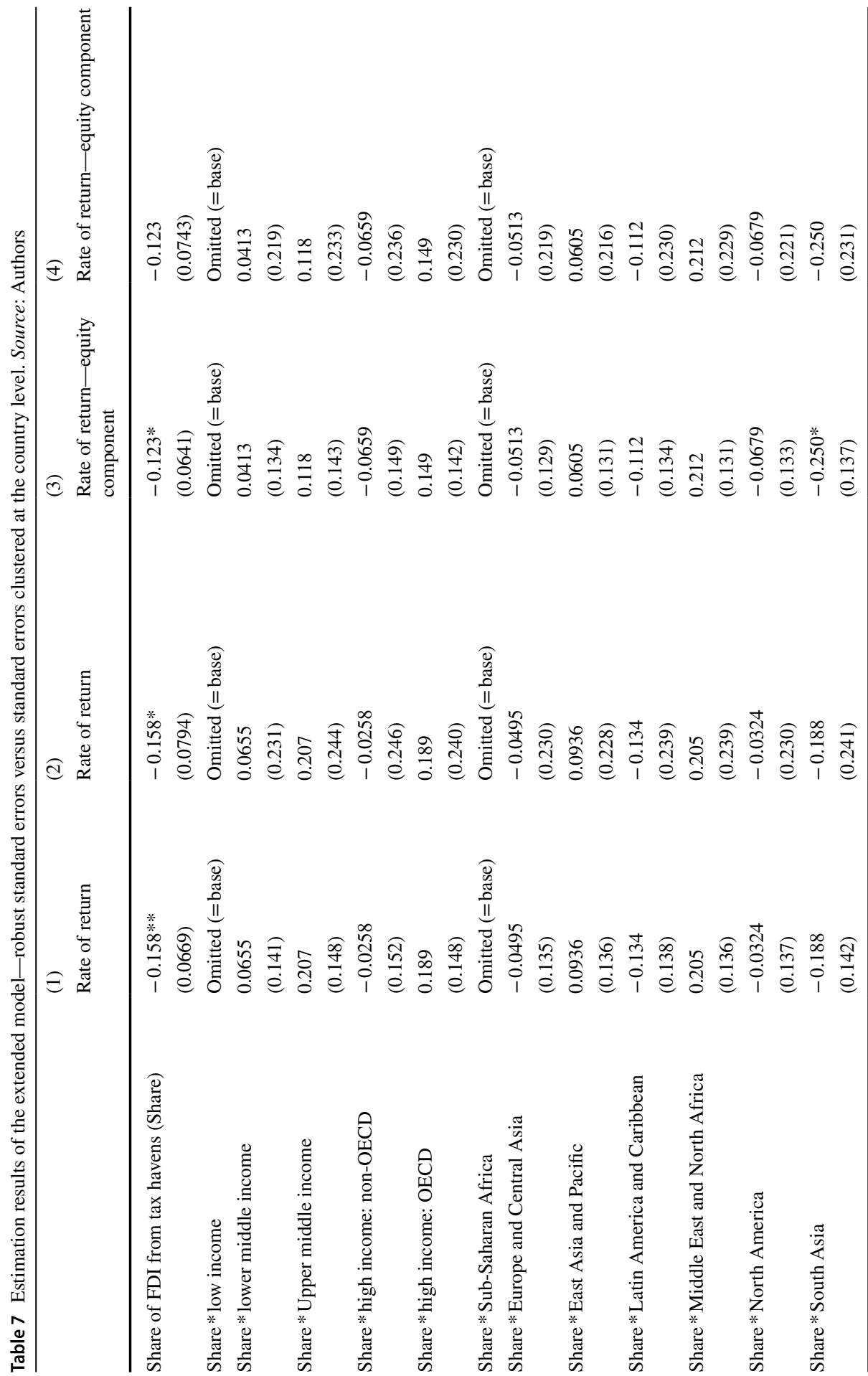




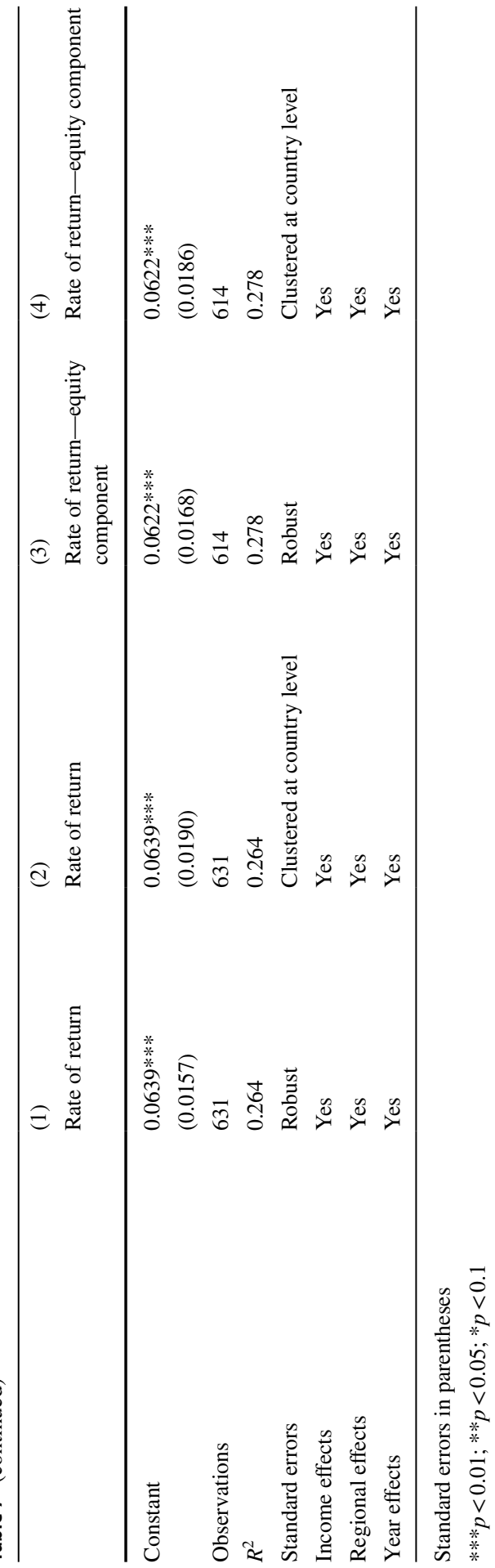


Table 8 Results of the estimation of the extended model-summary of region-income group combinations. Source: Authors

\begin{tabular}{|c|c|c|c|c|}
\hline Region & Income group & ROR method & $\begin{array}{l}\text { ROR_equity } \\
\text { component } \\
\text { method }\end{array}$ & $\begin{array}{l}\text { No. of } \\
\text { countries }\end{array}$ \\
\hline South Asia & Low income & $\begin{array}{l}-0.346^{* * *} \\
(0.223)\end{array}$ & $\begin{array}{l}-0.372 * * \\
(0.215)\end{array}$ & 1 \\
\hline South Asia & Lower middle income & $\begin{array}{l}-0.281 * * * \\
(0.196)\end{array}$ & $\begin{array}{l}-0.331 * * * \\
(0.191)\end{array}$ & 5 \\
\hline Latin America and Caribbean & High income: non-OECD & $\begin{array}{l}-0.317 * * * \\
(0.032)\end{array}$ & $\begin{array}{l}-0.3 * * * \\
(0.037)\end{array}$ & 4 \\
\hline Europe and Central Asia & High income: non-OECD & $\begin{array}{l}-0.233 * * * \\
(0.053)\end{array}$ & $\begin{array}{l}-0.24 * * * \\
(0.054)\end{array}$ & 4 \\
\hline Latin America and Caribbean & Lower middle income & $\begin{array}{l}-0.226^{* * * *} \\
(0.055)\end{array}$ & $\begin{array}{l}-0.193 * * * \\
(0.068)\end{array}$ & 4 \\
\hline Europe and Central Asia & Lower middle income & $\begin{array}{l}-0.142 * * * \\
(0.029)\end{array}$ & $\begin{array}{l}-0.133^{* * * *} \\
(0.025)\end{array}$ & 7 \\
\hline East Asia and Pacific & High income: non-OECD & $\begin{array}{l}-0.09 \\
(0.056)\end{array}$ & $\begin{array}{l}-0.128 \\
(0.072)\end{array}$ & 1 \\
\hline Sub-Saharan Africa & Low income & $\begin{array}{l}-0.158 * * \\
(0.018)\end{array}$ & $\begin{array}{l}-0.123^{*} \\
(0.018)\end{array}$ & 8 \\
\hline Latin America and Caribbean & Upper middle income & $\begin{array}{l}-0.084 \\
(0.06)\end{array}$ & $\begin{array}{l}-0.116^{* * *} \\
(0.067)\end{array}$ & 4 \\
\hline Latin America and Caribbean & High income: OECD & $\begin{array}{l}-0.103 * \\
(0.063)\end{array}$ & $\begin{array}{l}-0.085 \\
(0.069)\end{array}$ & 1 \\
\hline Sub-Saharan Africa & Lower middle income & $\begin{array}{l}-0.092 \\
(0.137)\end{array}$ & $\begin{array}{l}-0.081 \\
(0.128)\end{array}$ & 4 \\
\hline Europe and Central Asia & Upper middle income & $\begin{array}{l}0 \\
(0.047)\end{array}$ & $\begin{array}{l}-0.056 \\
(0.042)\end{array}$ & 11 \\
\hline North America & High income: OECD & $\begin{array}{l}-0.002 \\
(0.025)\end{array}$ & $\begin{array}{l}-0.041 \\
(0.026)\end{array}$ & 2 \\
\hline Europe and Central Asia & High income: OECD & $\begin{array}{l}-0.019 \\
(0.019)\end{array}$ & $\begin{array}{l}-0.025 \\
(0.02)\end{array}$ & 17 \\
\hline East Asia and Pacific & Lower middle income & $\begin{array}{l}0.001 \\
(0.023)\end{array}$ & $\begin{array}{l}-0.021 \\
(0.031)\end{array}$ & 4 \\
\hline Sub-Saharan Africa & Upper middle income & $\begin{array}{l}0.049 \\
(0.139)\end{array}$ & $\begin{array}{l}-0.004 \\
(0.133)\end{array}$ & 2 \\
\hline
\end{tabular}

Standard errors in parentheses

$* * * p<0.01 ; * * p<0.05 ; * p<0.1$ 


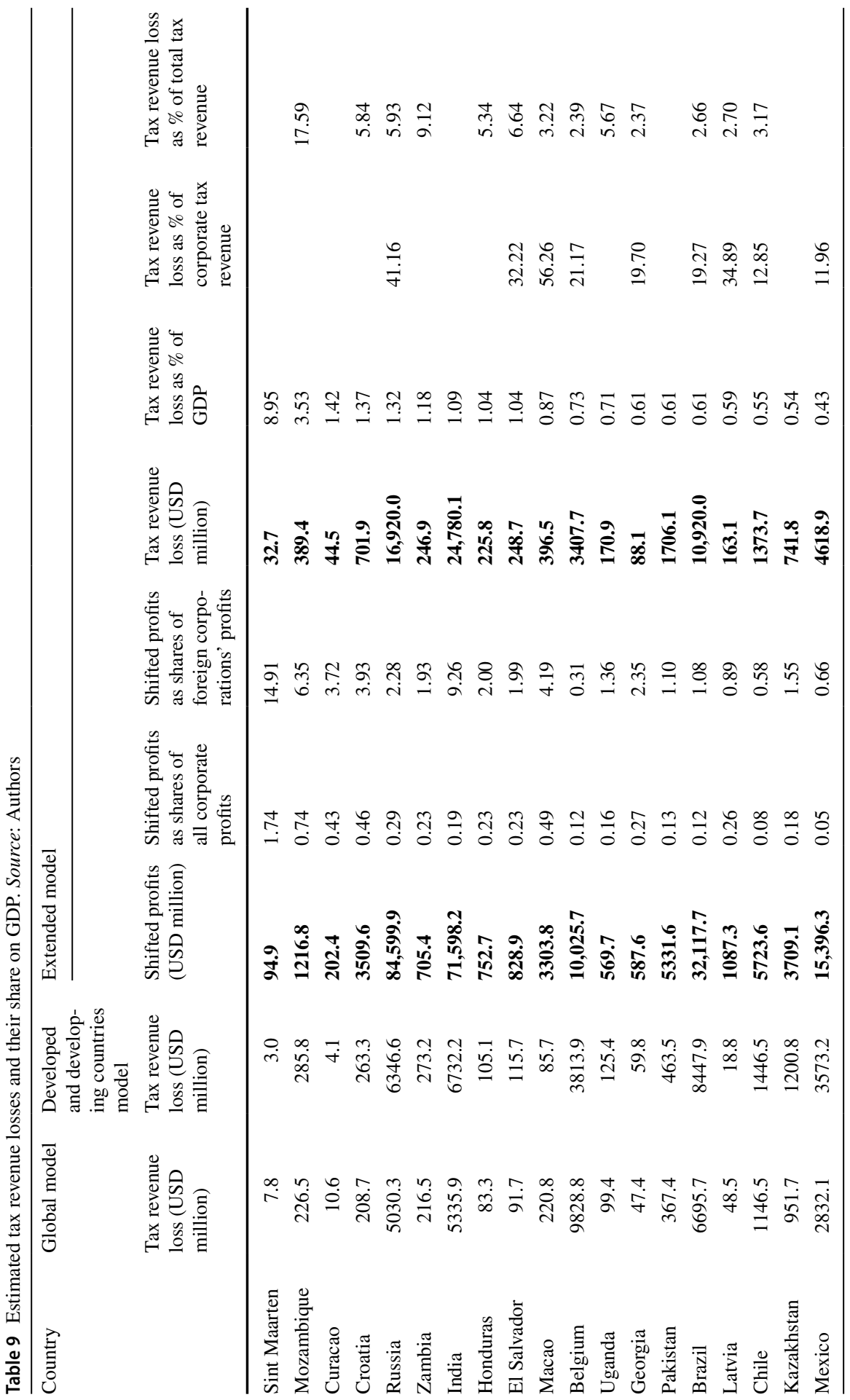




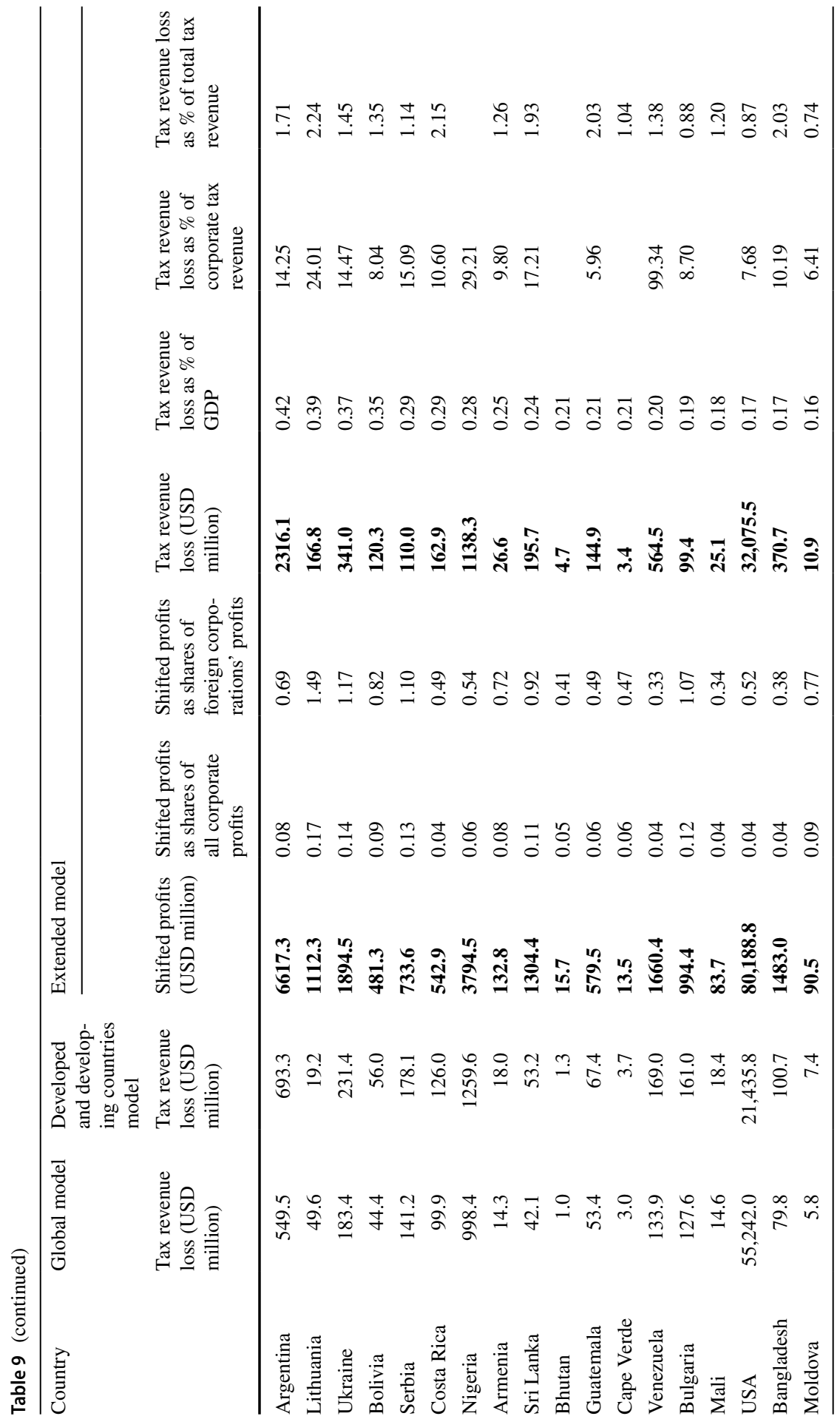




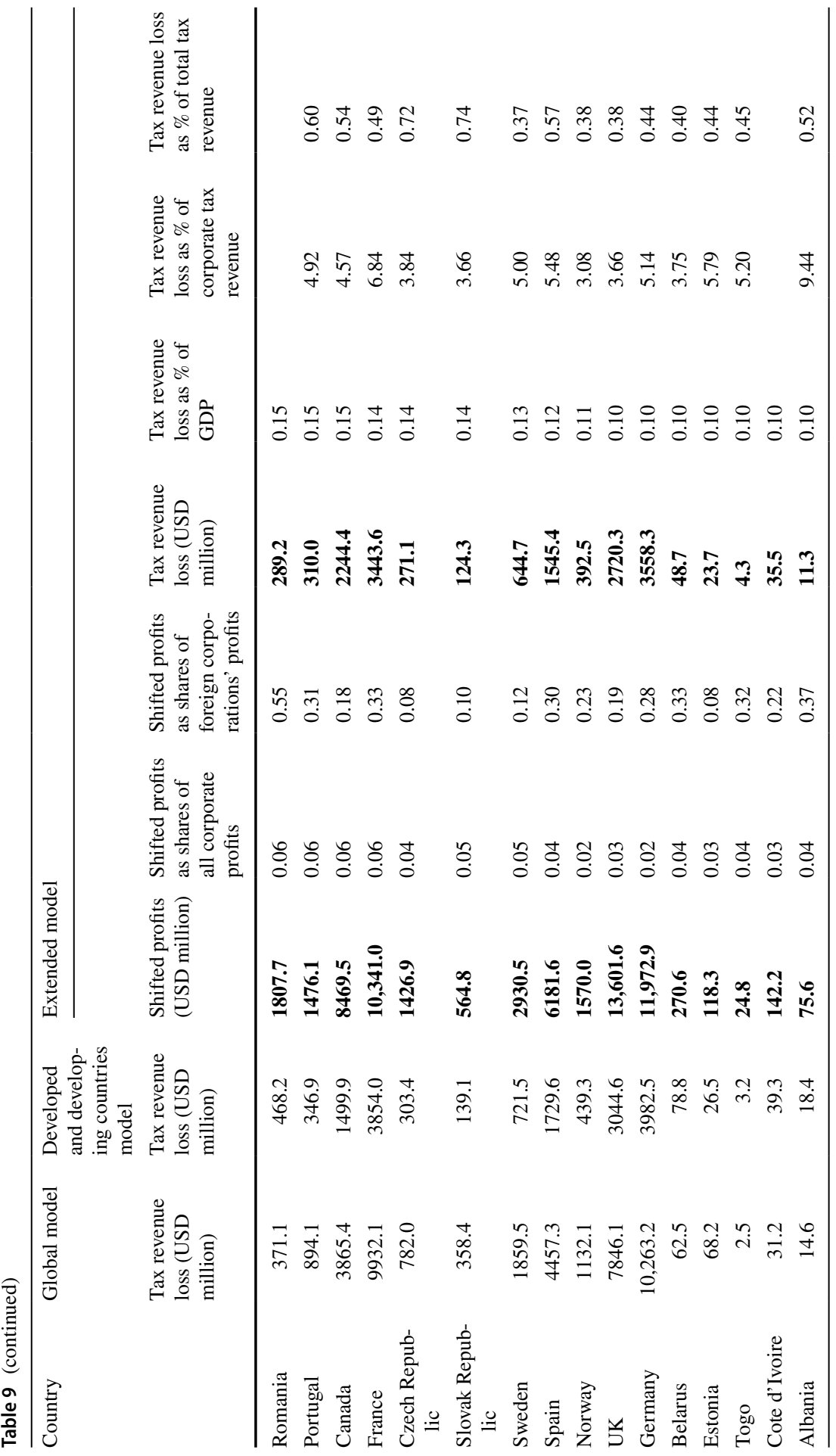




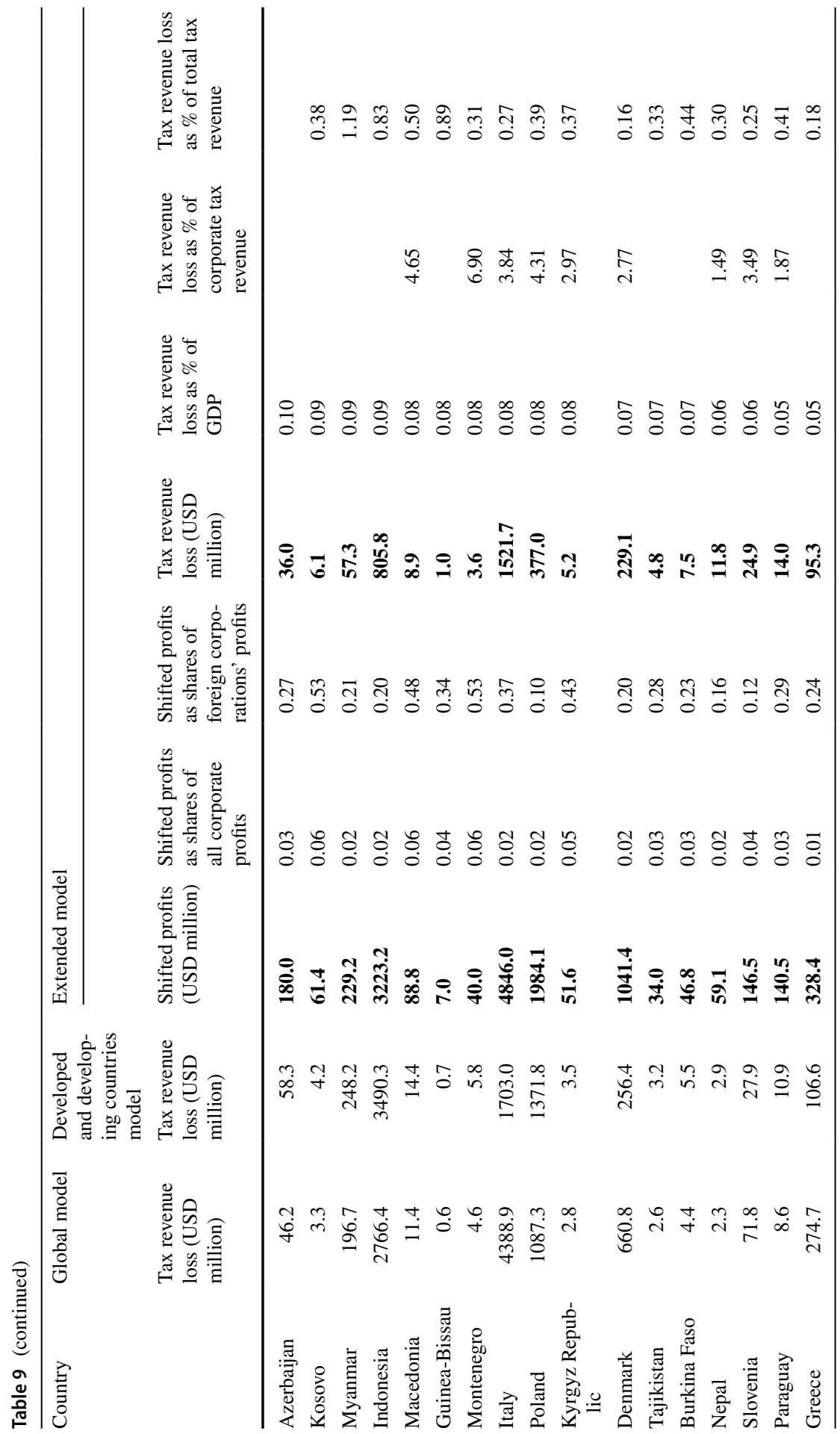




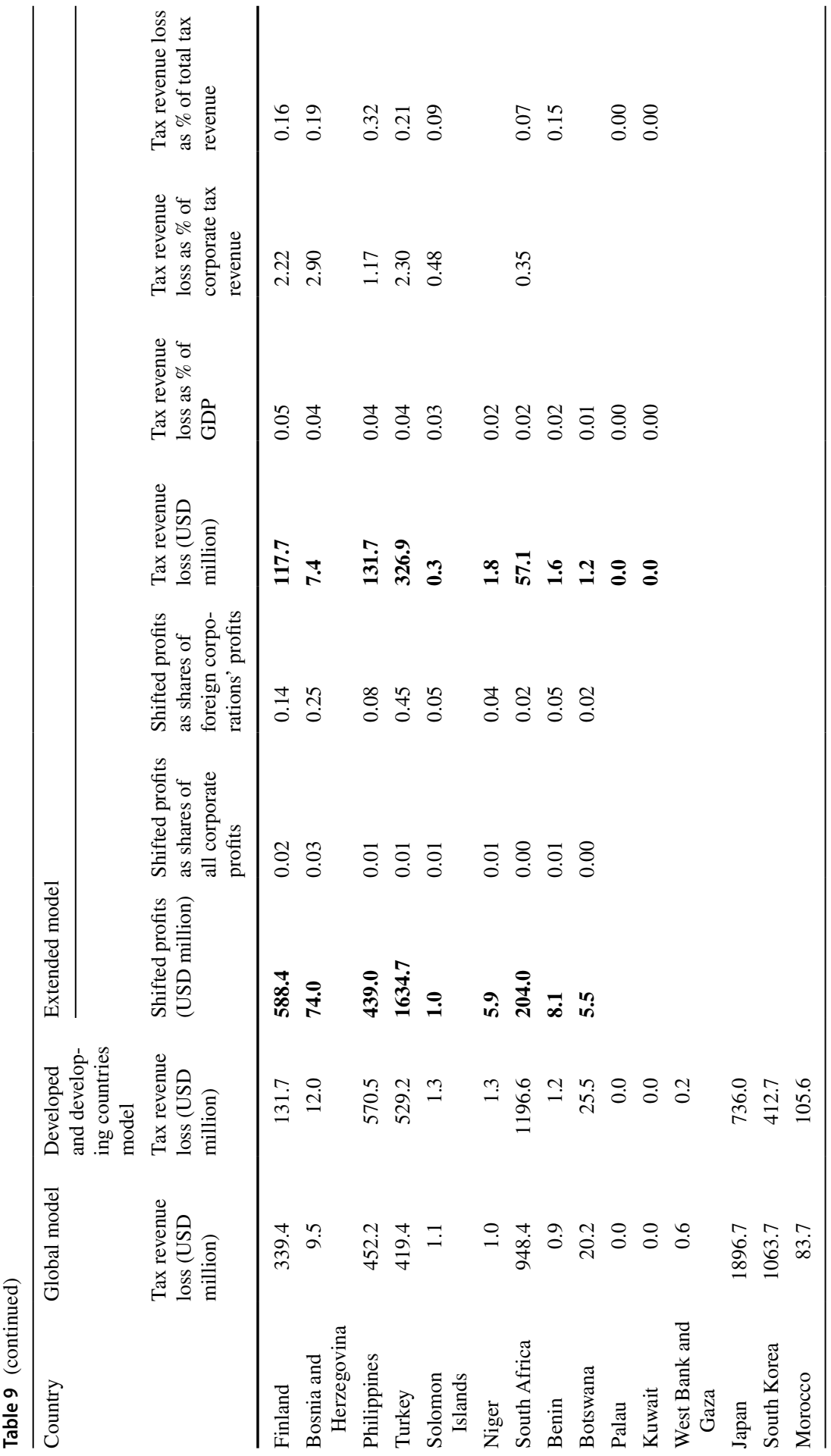




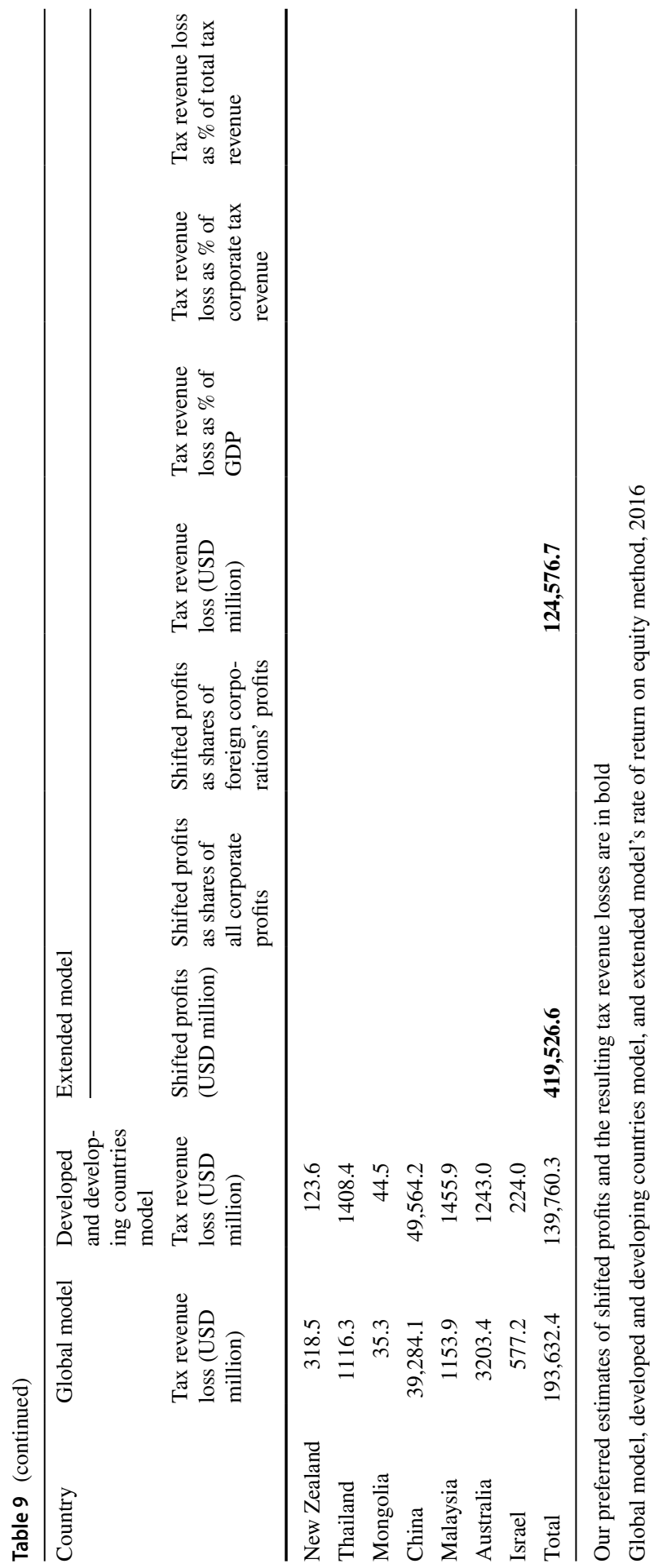




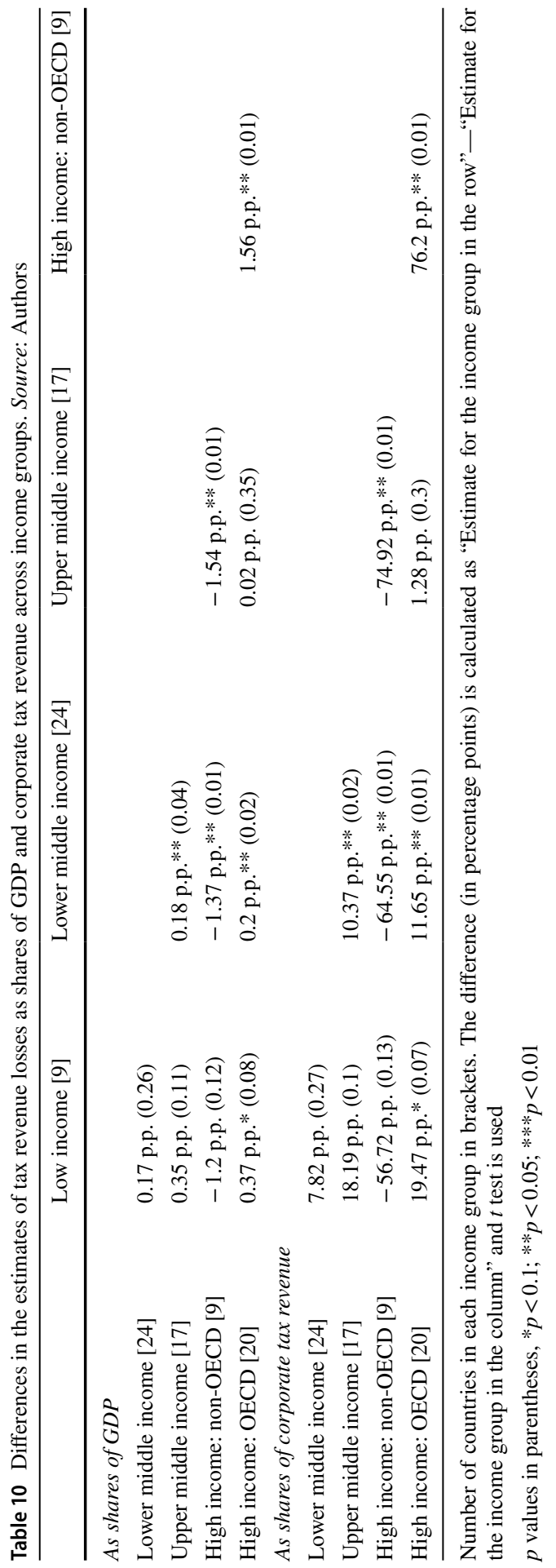




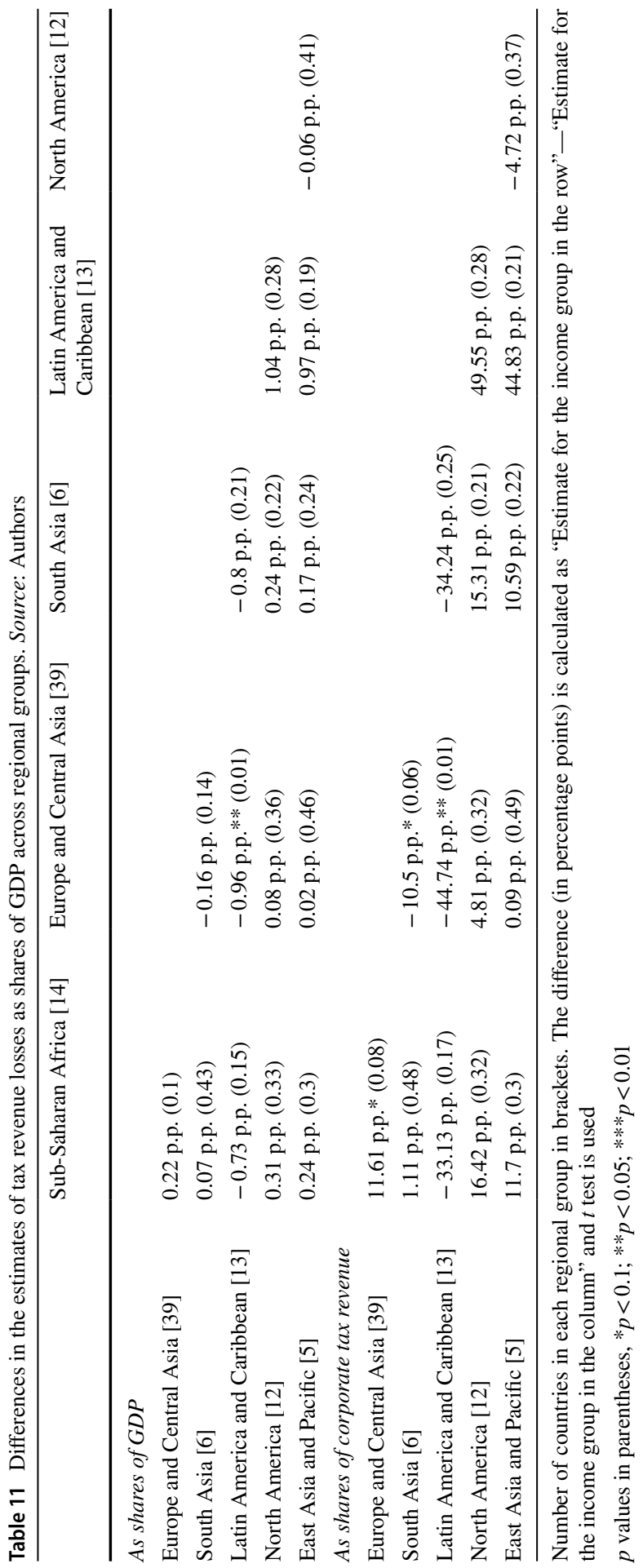


Table 12 Differences in the estimates of tax revenue losses as shares of GDP and corporate tax revenue across three income groups. Source: Authors
Table 13 Differences in the estimates of tax revenue losses as shares of GDP and corporate tax revenue across three groups of countries based on development status. Source: Authors; data on development status from UNCTADStat as of February 2019

\begin{tabular}{|c|c|c|}
\hline & Low income [9] & Middle income [41] \\
\hline \multicolumn{3}{|l|}{ As shares of $G D P$} \\
\hline Middle income [41] & 0.24 p.p. (0.12) & \\
\hline High income [29] & -0.12 p.p. $(0.42)$ & -0.36 p.p.* ${ }^{*}(0.09)$ \\
\hline \multicolumn{3}{|c|}{ As shares of corporate tax revenue } \\
\hline Middle income [41] & 12.12 p.p. $(0.12)$ & \\
\hline High income [29] & -4.17 p.p. $(0.44)$ & -16.3 p.p. $(0.11)$ \\
\hline
\end{tabular}

Number of countries in each income group in brackets. The difference (in percentage points) is calculated as "Estimate for the income group in the row"- "Estimate for the income group in the column" and $t$ test is used

$p$ values in parentheses, ${ }^{*} p<0.1 ; * * p<0.05 ; * * * p<0.01$

\begin{tabular}{lll}
\hline & Developing [39] & Transition [16] \\
\hline $\begin{array}{ll}\text { As shares of GDP } \\
\text { Transition [16] }\end{array}$ & 0.39 p.p. (0.16) & \\
Developed [24] & 0.43 p.p.* (0.08) & 0.04 p.p. (0.33) \\
As shares of corporate tax revenue & \\
Transition [16] & 19.97 p.p. (0.14) & \\
Developed [24] & 20.86 p.p.* (0.09) & 0.9 p.p. (0.42) \\
\hline
\end{tabular}

Number of countries in each income group in brackets. The difference (in percentage points) is calculated as "Estimate for the income group in the row"- "Estimate for the income group in the column" and $t$ test is used

$p$ values in parentheses, ${ }^{*} p<0.1, * * p<0.05, * * * p<0.01$

Table 14 Number of countries covered by each study in each income group. Source: Authors; results from Tørsløv et al. (2018), Cobham and Janský (2018, 2019a), and Clausing (2016)

\begin{tabular}{|c|c|c|c|c|c|c|}
\hline Study & Low income & $\begin{array}{l}\text { Lower } \\
\text { middle } \\
\text { income }\end{array}$ & $\begin{array}{l}\text { Upper } \\
\text { middle } \\
\text { income }\end{array}$ & $\begin{array}{l}\text { High } \\
\text { income: } \\
\text { non-OECD }\end{array}$ & $\begin{array}{l}\text { High } \\
\text { income: } \\
\text { OECD }\end{array}$ & $\begin{array}{l}\text { Total number } \\
\text { of countries }\end{array}$ \\
\hline Our estimates & 9 & 24 & 17 & 9 & 20 & 79 \\
\hline Tørsløv et al. (2018) & 0 & 1 & 7 & 2 & 27 & 37 \\
\hline $\begin{array}{l}\text { Cobham and Janský } \\
\text { (2018) }\end{array}$ & 24 & 29 & 20 & 7 & 22 & 102 \\
\hline $\begin{array}{l}\text { Cobham and Janský } \\
\text { (2019a) }\end{array}$ & 0 & 3 & 10 & 3 & 18 & 34 \\
\hline Clausing (2016) & 0 & 2 & 5 & 2 & 16 & 25 \\
\hline
\end{tabular}


Table 15 Share of GDP covered by each study in each income group. Source: Authors; results from Tørsløv et al. (2018), Cobham and Janský (2018, 2019a), and Clausing (2016)

\begin{tabular}{|c|c|c|c|c|c|c|}
\hline Study & $\begin{array}{l}\text { Low } \\
\text { income } \\
(\%)\end{array}$ & $\begin{array}{l}\text { Lower mid- } \\
\text { dle income } \\
(\%)\end{array}$ & $\begin{array}{l}\text { Upper mid- } \\
\text { dle income } \\
(\%)\end{array}$ & $\begin{array}{l}\text { High income: } \\
\text { non-OECD } \\
(\%)\end{array}$ & $\begin{array}{l}\text { High } \\
\text { income: } \\
\text { OECD (\%) }\end{array}$ & $\begin{array}{l}\text { All } \\
\text { coun- } \\
\text { tries } \\
(\%)\end{array}$ \\
\hline Our estimates & 26 & 82 & 25 & 45 & 77 & 62 \\
\hline Tørsløv et al. (2018) & 0 & 38 & 85 & 26 & 95 & 83 \\
\hline $\begin{array}{l}\text { Cobham and Janský } \\
\text { (2018) }\end{array}$ & 76 & 77 & 69 & 12 & 95 & 81 \\
\hline $\begin{array}{l}\text { Cobham and Janský } \\
\text { (2019a) }\end{array}$ & 0 & 43 & 83 & 46 & 91 & 82 \\
\hline Clausing (2016) & 0 & 53 & 83 & 38 & 82 & 77 \\
\hline
\end{tabular}




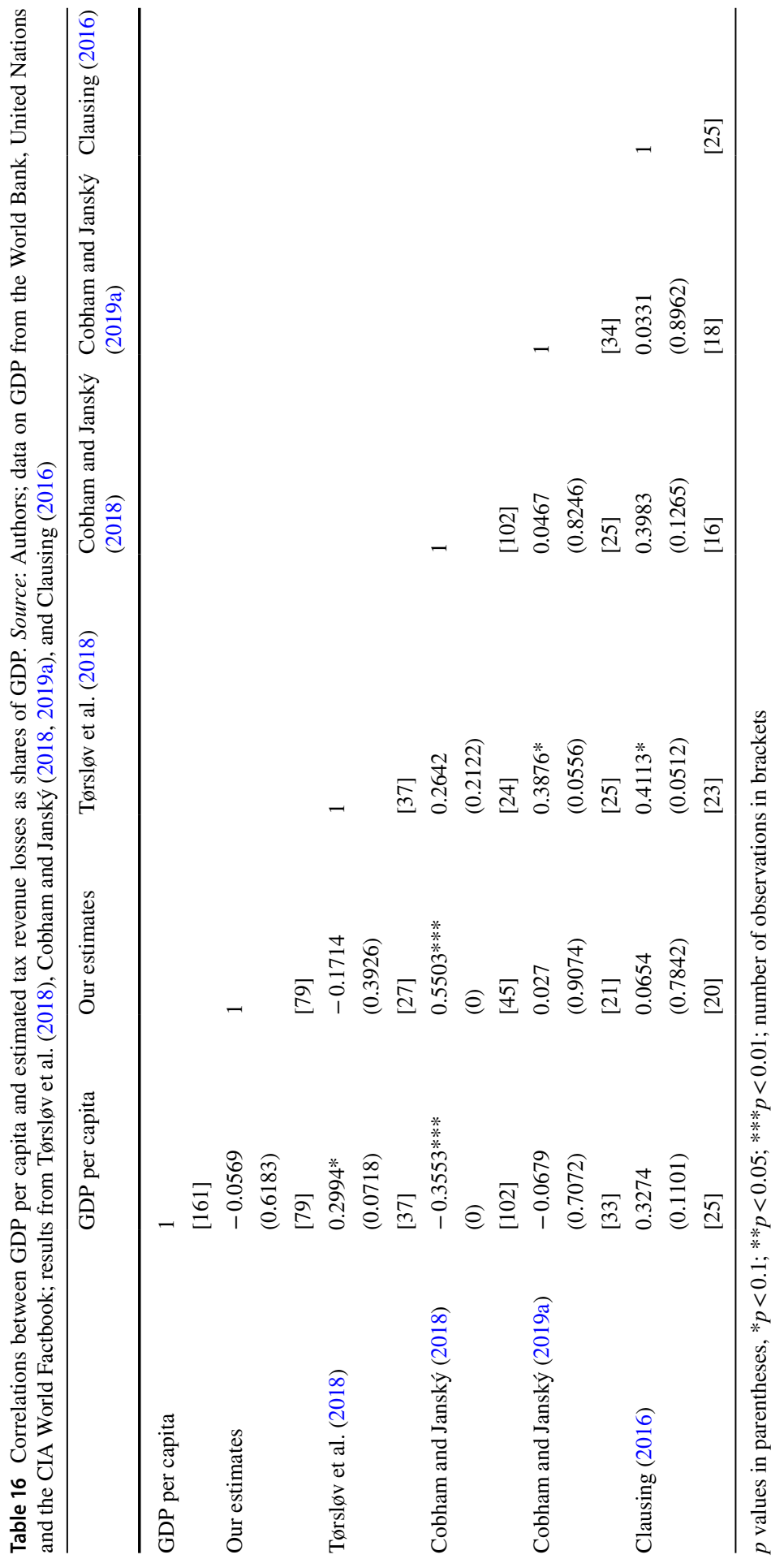




\section{References}

Akkermans, D. H. M. (2017). Net profit flow per country from 1980 to 2009: The long-term effects of foreign direct investment. PLOS ONE, 12(6), e0179244. https://doi.org/10.1371/journal.pone.01792 44.

Alstadsæter, A., Johannesen, N., \& Zucman, G. (2019). Tax evasion and inequality. American Economic Review (forthcoming).

Bartelsman, E. J., \& Beetsma, R. M. (2003). Why pay more? Corporate tax avoidance through transfer pricing in OECD countries. Journal of Public Economics, 87(9-10), 2225-2252.

Bilicka, K. A. (2019). Comparing UK tax returns of foreign multinationals to matched domestic firms. American Economic Review (forthcoming).

Bolwijn, R., Casella, B., \& Rigo, D. (2018a). An FDI-driven approach to measuring the scale and economic impact of BEPS. Transnational Corporations, 25(2), 107-144.

Bolwijn, R., Casella, B., \& Rigo, D. (2018b). Establishing the baseline: Estimating the fiscal contribution of multinational enterprises. Transnational Corporations, 25(3), 111-143.

Bryan, D., Rafferty, M., \& Wigan, D. (2017). Capital unchained: Finance, intangible assets and the double life of capital in the offshore world. Review of International Political Economy, 24(1), 56-86.

Buettner, T., \& Wamser, G. (2013). Internal debt and multinational profit shifting: Empirical evidence from firm-level panel data. National Tax Journal, 66(1), 63.

CIA. (2018). World Factbook. Retrieved September 20, 2018, from https://www.cia.gov/library/publi cations/the-world-factbook/.

Clausing, K. A. (2003). Tax-motivated transfer pricing and US intrafirm trade prices. Journal of Public Economics, 87(9-10), 2207-2223. https://doi.org/10.1016/S0047-2727(02)00015-4.

Clausing, K. A. (2009). Multinational firm tax avoidance and tax policy. National Tax Journal, 62(4), $703-725$.

Clausing, K. A. (2016). The effect of profit shifting on the corporate tax base in the United States and Beyond. National Tax Journal, 69(4), 905-934. https://doi.org/10.17310/ntj.2016.4.09.

Cobham, A., \& Janský, P. (2018). Global distribution of revenue loss from corporate tax avoidance: Reestimation and country results. Journal of International Development, 30(2), 206-232. https://doi. org/10.1002/jid.3348.

Cobham, A., \& Janský, P. (2019a). Measuring Misalignment: The location of US Multinationals' economic activity versus the location of their profits. Development Policy Review. https://doi. org/10.1111/dpr.12315.

Cobham, A., \& Janský, P. (2019b). Estimating illicit financial flows: A critical guide to the data, methodologies and findings. Retrieved February 5, 2019, from https://tax-justice-network.gitbooks.io/ourbook-project/content/.

Cobham, A., Janský, P., \& Meinzer, M. (2015). The financial secrecy index: Shedding new light on the geography of secrecy. Economic Geography, 91(3), 281-303.

Cobham, A., \& Loretz, S. (2014). International distribution of the corporate tax base: Implications of different apportionment factors under Unitary Taxation (pp. 1-38). Retrieved May 20, 2018, from http://ictd.ac/sites/default/files/ICTD\%20WP27.pdf.

Crivelli, E., de Mooij, R., \& Keen, M. (2016). Base Erosion profit shifting and developing countries. FinanzArchiv: Public Finance Analysis, 72(3), 268-301. https://doi.org/10.1628/001522116X 14646834385460 .

Damgaard, J., \& Elkjaer, T. (2017). The global FDI network: Searching for ultimate investors. IMF Working Paper, 17(258).

Davies, R. B., Martin, J., Parenti, M., \& Toubal, F. (2018). Knocking on tax haven's door: Multinational firms and transfer pricing. Review of Economics and Statistics, 100(1), 120-134.

Desai, M. A. (2005). The degradation of reported corporate profits. Journal of Economic Perspectives, 19(4), 171-192.

Dharmapala, D. (2014). What do we know about base erosion and profit shifting? A review of the empirical literature. Fiscal Studies, 35(4), 421-448. https://doi.org/10.111 1/j.1475-5890.2014.12037.x.

Dharmapala, D., \& Riedel, N. (2013). Earnings shocks and tax-motivated income-shifting: Evidence from European multinationals. Journal of Public Economics, 97, 95-107.

Dischinger, M., \& Riedel, N. (2011). Corporate taxes and the location of intangible assets within multinational firms. Journal of Public Economics, 95(7), 691-707. 
Dowd, T., Landefeld, P., \& Moore, A. (2017). Profit shifting of U.S. multinationals. Journal of Public Economics, 148, 1-13. https://doi.org/10.1016/j.jpubeco.2017.02.005.

Fuest, C., Hebous, S., \& Riedel, N. (2011). International debt shifting and multinational firms in developing economies. Economics Letters, 113(2), 135-138.

Fuest, C., \& Riedel, N. (2012). Tax Evasion and tax avoidance: The role of international profit shifting. In P. Reuter (Ed.), Draining development? Controlling flows of illicit funds from developing countries (pp. 109-142). Retrieved from https://openknowledge.worldbank.org/handle/10986/2242.

Garcia-Bernardo, J., Fichtner, J., Takes, F. W., \& Heemskerk, E. M. (2017). Uncovering Offshore Financial Centers: Conduits and sinks in the Global Corporate Ownership Network. Scientific Reports, 7(1), 6246. https://doi.org/10.1038/s41598-017-06322-9.

Gravelle, J. G. (2015). Tax havens: International tax avoidance and evasion. Washington DC: Congressional Research Service.

Gumpert, A., Hines, J. R., \& Schnitzer, M. (2016). Multinational firms and tax havens. The Review of Economics and Statistics, 98(4), 713-727. https://doi.org/10.1162/REST_a_00591.

Guvenen, F., Mataloni, R. J., Jr., Rassier, D. G., \& Ruhl, K. J. (2017). Offshore profit shifting and domestic productivity measurement. Cambridge: National Bureau of Economic Research.

Haberly, D., \& Wójcik, D. (2015). Tax havens and the production of offshore FDI: An empirical analysis. Journal of Economic Geography, 15(1), 75-101. https://doi.org/10.1093/jeg/lbu003.

Heckemeyer, J. H., \& Overesch, M. (2017). Multinationals' profit response to tax differentials: Effect size and shifting channels. Canadian Journal of Economics, 50(4), 965-994. https://doi. org/10.1111/caje.12283.

Hines, J. R., \& Rice, E. M. (1994). Fiscal paradise: Foreign tax havens and American business. The Quarterly Journal of Economics, 109(1), 149-182.

Huizinga, H., \& Laeven, L. (2008). International profit shifting within multinationals: A multi-country perspective. Journal of Public Economics, 92(5), 1164-1182.

ICTD/UNU-WIDER. (2018). Government revenue dataset. Retrieved October 2, 2018, from https:// www.wider.unu.edu/project/government-revenue-dataset.

IMF. (2013). Sixth Edition of the IMF's Balance of Payments and International Investment Position Manual (BPM6). Retrieved May 20, 2018, from http://www.imf.org/external/pubs/ft/bop/2007/ bopman6.htm.

IMF. (2014). Spillovers in international corporate taxation. Retrieved May 20, 2018, from International Monetary Fund website: http://www.imf.org/external/np/pp/eng/2014/050914.pdf.

IMF. (2018). Coordinated direct investment survey. Retrieved June 5, 2018, from http://data.imf.org/ CDIS.

Johannesen, N., \& Pirttilä, J. (2016). Capital flight and development: An overview of concepts, methods, and data sources. UNU-WIDER Working Paper Series, 2016(19), 1-18.

Johannesen, N., Tørsløv, T., \& Wier, L. (2017). Are less developed countries more exposed to multinational tax avoidance? Method and evidence from micro-data. WIDER Working Paper, 2016(10), 1-30.

Johansson, A., Skeie, O. B., Sorbe, S., \& Menon, C. (2017). Tax planning by multinational firms: Firmlevel evidence from a cross-country database. OECD Economics Department Working Papers, 2017(1355), 64. https://doi.org/10.1787/9ea89b4d-en.

Kalemli-Ozcan, S., Sorensen, B., Villegas-Sanchez, C., Volosovych, V., \& Yesiltas, S. (2015). How to Construct Nationally Representative Firm Level data from the ORBIS Global Database (Working Paper No. 21558). Retrieved from National Bureau of Economic Research website: http://www. nber.org/papers/w21558.

Karkinsky, T., \& Riedel, N. (2012). Corporate taxation and the choice of patent location within multinational firms. Journal of International Economics, 88(1), 176-185.

KPMG. (2018). Corporate tax rates table. Retrieved November 10, 2018, from https://home.kpmg.com/ $\mathrm{xx} / \mathrm{en} / \mathrm{home} / \mathrm{services/tax} /$ tax-tools-and-resources/tax-rates-online/corporate-tax-rates-table.html.

OECD. (2000). Towards global tax co-operation: Report to the 2000 Ministerial Council Meeting and Recommendations by the Committee on Fiscal Affairs: Progress in Identifying and Eliminating Harmful Tax Practices. Retrieved April 11, 2018, from OECD website: http://www.oecd.org/tax/ transparency/44430257.pdf.

OECD. (2015a). Measuring and monitoring BEPS, Action 11-2015 final report. Retrieved April 25, 2018, from http://www.oecd-ilibrary.org/content/book/9789264241343-en.

OECD. (2015b). Measuring international investment by multinational enterprises. Retrieved February 25, 2018, from OECD website: http://www.oecd-ilibrary.org/content/book/9789264241343-en. 
OECD. (2017). OECD Transfer pricing guidelines for multinational enterprises and tax administrations 2017. Retrieved June 7, 2018, from http://dx.doi.org/10.1787/tpg-2017-en.

OECD. (2018). OECD/G20 inclusive framework on BEPS: progress report July 2017-June 2018OECD. Retrieved September 14, 2018, from http://www.oecd.org/ctp/inclusive-framework-on-bepsprogress-report-june-2017-july-2018.htm.

Peralta, S., Wauthy, X., \& Van Ypersele, T. (2006). Should countries control international profit shifting? Journal of International Economics, 68(1), 24-37.

Pérez, M. F., Brada, J. C., \& Drabek, Z. (2012). Illicit money flows as motives for FDI. Journal of Comparative Economics, 40(1), 108-126.

Reynolds, H., \& Wier, L. (2016). Estimating profit shifting in South Africa using firm-level tax returns. WIDER Working Paper Series, 2016(128), 1-19.

Seabrooke, L., \& Wigan, D. (2015). How activists use benchmarks: Reformist and revolutionary benchmarks for global economic justice. Review of International Studies, 41(5), 887-904.

Taylor, G., Richardson, G., \& Lanis, R. (2015). Multinationality, tax havens, intangible assets, and transfer pricing aggressiveness: An empirical analysis. Journal of International Accounting Research, 14(1), 25-57.

Tørsløv, T. R., Wier, L. S., \& Zucman, G. (2018). The Missing Profits of Nations (Working Paper No. 24701). https://doi.org/10.3386/w24701.

UNCTAD. (2015). World Investment Report 2015-Reforming International Investment Governance. Geneva: United Nations.

United Nations. (2018). Gross domestic product data. Retrieved October 23, 2018, from http://data. un.org/.

World Bank. (2016). Doing Business 2017: Equal opportunity for all. Washington, DC: World Bank.

Wright, T., \& Zucman, G. (2018). The exorbitant tax privilege. (Working Paper No. 24983). Retrieved from National Bureau of Economic Research website: http://www.nber.org/papers/w24983.

Zucman, G. (2014). Taxing across borders: Tracking personal wealth and corporate profits. Journal of Economic Perspectives, 28(4), 121-148.

Publisher's Note Springer Nature remains neutral with regard to jurisdictional claims in published maps and institutional affiliations. 